\title{
Temporal and Spatial Integration in the Rat SI Vibrissa Cortex
}

\author{
DANIEL J. SIMONS \\ Center for Neuroscience and Department of Physiology, \\ University of Pittsburgh School of Medicine, Pittsburgh, Pennsylvania 15261
}

\section{SUMMARY AND CONCLUSIONS}

1. Glass micropipettes were used to record the activity of 124 single units in the somatosensory vibrissa cortex (SI) of 16 rats in response to combined deflections of contralateral vibrissae. Compact multiangular electromechanical stimulators were used to stimulate individual vibrissal hairs alone or in combinations of two or three adjacent whiskers. Each whisker was stimulated independently to produce controlled temporal and spatial patterns of mechanical stimuli.

2. Following displacement of a vibrissa, unit discharges to subsequent deflections of adjacent whiskers are reduced in a time-dependent fashion. Response suppression is strongest at short interdeflection intervals, i.e., 10-20 ms and decreases progressively during the $50-100 \mathrm{~ms}$ following the first deflection. In many cases this period also corresponds with a reduction in ongoing unit discharges.

3. Response suppression was not observed for first-order neurons recorded in the trigeminal ganglion of barbiturate-anesthetized rats.

4. In the cortex, the presence and/or degree of response suppression depends on a number of spatial factors. Thesc include 1 ) the angular direction(s) in which the individual hairs are moved, 2) the sequence in which two whiskers are deflected, that is, which one is deflected first, 3) the particular combination of whiskers stimulated, and 4 ) the number ( 2 or 3 ) of vibrissae comprising the multiwhisker stimulus.

5. Within a vertical electrode penetration, one particular whisker typically elicits the strongest excitatory and inhibitory effects; other, nearby vibrissae elicit variable (or no) excitation or inhibition. Excitatory and inhibitory subregions of a receptive field could thus be distributed asymmetrically around the maximally effective whisker. In these cases, the receptive fields displayed spatial orientations.

6. Quantitative criteria were used to classify 30 cortical units on the basis of the distribution of inhibitory subregions on either side of the maximally effective whisker. Twenty-one of these cells had receptive fields (RFs) with symmetrical inhibitory side regions. Responses of the other nine units were strongly suppressed by a preceding deflection of a vibrissa on one side but relatively unaffected, or even slightly facilitated, by preceding deflection of the whisker on the other side. Most of these units with asymmetrically organized RF's were recorded in the decper aspects of the cortex $(\sim 1,100-2,000 \mu \mathrm{m}$ below the pial surface) where they constituted a majority of the classified cells.

7. Twenty-five units displayed distinct response peaks to each deflected whisker in a multiwhisker stimulus. For 20 of these cells such responses were obtained when the angular direction of the individual whisker displacements paralleled the spatial sequence of the deflections.

8. These findings suggest that neurons in the SI cortex, but not in the trigeminal ganglion, are differentially responsive to patterned stimuli produced by objects moving in particular directions and/or at certain velocities through the vibrissal field. Such processing of information appears to depend in part on intracortical mechanisms.

\section{INTRODUCTION}

The mystacial vibrissae of rats and some other rodents consist of 30-35 discrete tactile organs that form an array of complex receptor 
elements that is swept back and forth through the sensory environment during exploratory tactile behavior $(62,68)$. The follicles of each of the vibrissal hairs are innervated by as many as 200 large myelinated axons whose parent cell bodies are located in the trigeminal ganglion (63; see also Ref. 28). Physiological studies have demonstrated that these first-order afferent fibers functionally innervate not more than one whisker (79; see also Refs. 8, 14) and that this segregated pattern of innervation is largely maintained in the representation of the vibrissae in the brain stem $(40,49)$ and thalamic nuclei $(9,64$; see also Ref. 61$)$ which comprise the main sensory pathway to the somatosensory cortex. This discrete and highly specific projection is paralleled in the somatosensory vibrissa cortex (SI) by the presence of distinct aggregations of cells in layer IV, called barrels, whose spatial organization closely reflects the pattern of vibrissae on the contralateral face $(66,77)$. Numerous studies using a variety of anatomical and physiological techniques have clearly demonstrated a oneto-one correspondence between a given mystacial vibrissa and its appropriate cortical barrel $(7,26,56,60,66,67,78)$.

The relation between vibrissae and barrels was first appreciated in evoked potential studies in mice (75). Subsequently, Welker (66, $67)$ found that units and unit clusters recorded in barbiturate-anesthetized rats were activated only by high-velocity deflections of not more than one whisker and were not differentially responsive to the angle in which that single hair was moved. An important observation was that these unit cluster responses could be precisely correlated with appropriate individual barrels. More recent studies of single cortical units in unanesthetized rats and mice (53, $55,56)$ have extended these findings by demonstrating that when electrodes are advanced through the barrel cortex, perpendicular to the pial surface, cells recorded at different cortical depths are all activated by at least one particular vibrissa; electrode track reconstructions show a direct correspondence between this "principal" whisker and its appropriate barrel. Additionally, these studies have revealed convergence of spatial information that is grcatest in the nongranular layers. Receptive-field sizes are smallest in layer IV, where the majority of cells are activated only by the whisker that is correct for the barrel in which the unit is recorded, and largest in layers V and VI where most cells respond to deflections of several adjacent whiskers, sometimes as many as 20 or more (see also Ref. 5). Moreover, under these conditions, cortical vibrissa units, like those in the periphery (79), respond differentially to a variety of stimulus parameters such as angular direction, velocity, amplitude, and frequency (see also Refs. 3, 24, 49). When a unit is activated by more than one whisker, the responses elicited by stimulation of different vibrissae comprising the receptive field are observed to be qualitatively similar, for example, all reveal a similar angular sensitivity.

These physiological data have been interpreted to mean that each barrel is the morphological correlate in layer IV of a functional cortical column that extends throughout the thickness of the cortex $(53,56$; see also Refs. 7,36 ). The findings also indicate that an important function of the SI cortex is to integrate information arising from different, individual vibrissae on the contralateral face. This spatial integration is thought to depend at least in part on a hierarchical organization whereby cells in different barrels, but with similar or related response properties, converge on specific neurons in the supra- and infragranular layers. To study how the barrel cortex processes information from groups of whiskers, an array of multiangular electromechanical stimulators has been developed that can be used to deflect independently a number of facial vibrissae in controlled spatial and temporal patterns. Use of these stimulators to deflect pairs of adjacent whiskers has identified several spatial factors that determine the responses of SI cortical neurons to multiwhisker stimuli (54). These include the angular direction of the hair movements, the spatial sequence in which the hairs are deflected, and the particular combination of whiskers involved. The present report describes these phenomena in more detail, including some of the temporal factors that underlie them. Moreover, evidence is provided that a number of spatial and temporal factors interact to synthesize direction-selective attributes of some cortical cells. Similar experiments on first-order neurons in the trigeminal ganglion indicate that these phenomena are not due to interactions in the sensory periphery 
but are brought about through integrative mechanisms within the central nervous system, possibly in the SI cortex itself.

\section{METHODS}

\section{Preparation and recording}

Surgical and electrophysiological procedures for recording extracellular unit potentials from the rodent somatosensory cortex (SI) were similar to those described previously $(53,56)$. Adult, femalc, albino rats weighing 150-275 g (Sprague-Dawley strain; Hilltop Lab Animals, Scottsdale, PA) were anesthetized with pentobarbital sodium (Nembutal, 50 $\mathrm{mg} / \mathrm{kg}$, ip) that was supplemented as needed to maintain areflexia to foot pinch throughout surgical preparation. A short length of polyethylene tubing was inserted into the trachea as a cannula, and a steel post was fixed to the exposed skull with dental acrylic. The latter was used to stabilize the animal's head without pressure points during the recording sessions. A small craniotomy $\left(\sim 0.5 \mathrm{~mm}^{2}\right)$ was made over the right SI vibrissa cortex, and the dura was carefully reflected. In later experiments, an attempt was made to expose cortex overlying the row- $\mathrm{C}$ or row-D vibrissae (e.g., C2 or C3, see below) as it was found most convenient to stimulate these larger, centrally located whiskers. An acrylic dam was constructed around the craniotomy and was filled with warm saline or mineral oil. Following infiltration of the surgical fields with a local anesthetic, the scalp and neck incisions were sutured closed to prevent dessication or irritation of the tissue.

While the animals were still anesthetized, they were positioned on the recording table where they were held only by the steel post previously affixed to the skull. Head orientation was adjusted to optimize positioning of the whisker stimulators (see below) in the immediate vicinity of the one whisker principally associated with the small cranial opening. This particular hair was readily determined by making an initial electrode penetration through the upper cortical layers because SI vibrissa units in barbiturate-anesthetized rats are activated almost exclusively by one "columnar" whisker (cf. 53, 66). Similar reductions in receptive-field size with different general anesthetics have been documented in other studies of the rodent SI cortex (6) and in other species as well $(34,35)$. Since the purpose of the present experiments was to examine integrative properties of SI neurons revealed by controlled stimuli involving both the columnar whisker and neighboring vibrissae, data were collected from unanesthetized animals whose whiskers were stationary. To do this, the rats werc subsequently allowed to recover from general anesthesia under neuromuscular blockade. Paralysis was maintained by a mixture of gallamine triethiodide and pancuronium bromide administered through an indwelling intraperitoneal cannula consisting of a 26-gauge syringe needle. Dosage was adjusted so that reflexive movements of the vibrissae or eye blinks could be elicited at intervals of $20-25 \mathrm{~min}$. The rats were artificially respired with a positive-pressure respirator that was adjusted as necessary to maintain endtidal $\mathrm{CO}_{2}$ levels at $3.5-4.5 \%(\sim 2.5 \mathrm{ml}$ at $80-100$ strokes/min). Rectal temperature was maintained at $37^{\circ} \mathrm{C}$ by a servo-controlled heating blanket. Ophthalmic ointment was applied to the eyes to prevent drying of the corneas, and throughout the remainder of the experiment surgical fields were periodically covered with $5.0 \%$ lidocaine (Xylocaine) ointment that was warmed to body temperature to reduce its viscosity.

Recording sessions began at least $2 \mathrm{~h}$ later and lasted 6-10 h. During this period no surgical procedures or physical manipulation of the surgical fields were performed, and the animals remained in the dimly illuminated and relatively quiet laboratory. Only innocuous somatic stimuli (small deflections of the facial vibrissae) were used in the experiments. The condition of the animals was assessed by frequent observation of the electrocardiogram, pupillary reflexes, and vascular perfusion of glabrous skin. Heart rate remained stable and well within the normal range for rats at rest (32). Pupils were miotic, even in low light levels, and constricted reflexively in response to light flashes. Electroencephalographic recordings in identically prepared and maintained animals in this laboratory show asynchronous activity of $\sim 10-12 \mathrm{~Hz}$ that is spontaneously interrupted by periods of synchronous, somewhat larger amplitude waves at $5-8 \mathrm{~Hz}$. Particularly in the longer experiments, it appeared that the rats became increasingly somnolent as evidenced by decreasing need for the paralytic agents and occasionally by diminished responsiveness of cortical cells to multiwhisker stimuli (see also Ref. 39). When the latter occurred, the experiments were terminated. At the conclusion of the recording sessions, the animals were killed by an overdose of barbiturate anesthetic administered through the intraperitoneal cannula; artificial respiration was continued until electrocardiographic activity ceased.

Glass microelectrodes filled with $3 \mathrm{M} \mathrm{NaCl}(\sim 1$ $\mu \mathrm{m}$ tip diameter, 6-12 $\mathrm{M} \Omega$ impedance) were oriented normal to the pial surface and advanced through the cortex by means of a hydraulic microdrive equipped with a digital counter. During advancement, whiskers on the contralateral (left) face were periodically deflected using hand-held probes so that units that were not spontaneously active could be isolated. In later experiments the electromechanical stimulators (see below) were used to randomly deflect whiskers in different angular 
directions as the electrode was advanced. Extracellular recordings were obtained from single cortical units as judged by spike waveform and amplitude criteria. An analog delay line was used for visualization of the entire spike waveform, and an amplitude discriminator was used to digitize the impulse events and to isolate the largest amplitude potentials when more than one unit was being recorded. The cortical depth of the recorded units was obtained from the microdrive counter. Although no attempt was made to histologically verify the laminar location of the recorded cells, unit sampling and changes in background activity levels at different cortical depths were comparable with those observed in previous studies in which electrode tracks were histologically reconstructed (e.g., Ref. 55).

\section{Stimulation}

The electromechanical stimulators used to independently deflect combinations of vibrissae have been described in detail previously (54). Briefly, the stimulators are constructed from two sets of piezoelectric bimorph "benders" (Vernitron Piezoelectric, Bedford, $\mathrm{OH}$ ) that are cemented together so that their planes of movement are orthogonal to each other. Separate driving signals are applied to each stage, and the resulting movement of the stimulator can be varied over $360^{\circ}$. A grass probe is used to amplify the displacements produced by the bimorphs. A stimulator is attached to a whisker by inserting the terminal $2 \mathrm{~mm}$ of the hair (that has been trimmed to a length of $7 \mathrm{~mm}$ ) into a short length of 30-gauge tubing that protrudes from the end of the probe. Stimulators are positioned over individual vibrissae by means of micromanipulators supported on steel or aluminum beams that are suspended beside the recording table. For the present experiments, two to five stimulators were attached to adjacent hairs, and whiskers were deflected alone or in combinations of two or three. Individual stimuli were ramp-and-hold "trapezoids" consisting of 1-mm displacements of $200 \mathrm{~ms}$ duration (see Fig. 1). Stimulus waveforms were filtered to produce sigmoidally shaped ramps with average velocities of 100 or $135 \mathrm{~mm} / \mathrm{s}$; with these stimuli, mechanical ringing of the stimulators was kept to $<10 \mu \mathrm{m}$. The stimulators were controlled by a laboratory computer that was also used to simultaneously acquire, store, and analyze the spike data. Spike interevent times were measured with a resolution of $100 \mu \mathrm{s}$ and retained in a format that allowed completc reconstruction of the spike discharge pattern for each stimulus presentation.

\section{Experimental procedures}

Once a unit was isolated, its receptive field was determined using hand-held probes, and the whisker eliciting the most vigorous responses was identified. Individual vibrissae were specified by row $(A$ through $E$, proceeding dorsal to ventral) and arc ( $I$ through 4-7, proceeding caudal to rostral: see figurine, Fig. 1). Whiskers straddling the rows at the caudal aspect of the face pad are labeled $\alpha, \beta, \gamma$, and $\delta$. Since electrode penetrations were oriented normal to the pia, and thus parallel to the long axis of a functional cortical column, the maximally effective whisker was usually the same for each unit encountered. This columnar whisker is called the principal whisker of the penetration. The angular sensitivity of each cell was determined using a mechanical stimulator to deflect the principal whisker in eight different directions (i.e., in $45^{\circ}$ increments relative to the horizontal alignment of whisker rows on the face). Stimuli were delivered randomly for each sequence of eight directions, and this was repeated 5-10 times for a total of 40-80 stimulus presentations. The mean discharge and variance during the $20 \mathrm{~ms}$ following the onset of the deflection was computed on-line, and a visual representation of the unit's angular preference was displayed on a graphics terminal in the form of a polar plot (see Fig. 1). These data were used to determine the cell's "best" or maximally activating angular direction.

A conditioning-test paradigm was used to study the responses of single neurons to combined displacements of two and, in later experiments, three individual vibrissae. Stimuli that were identical with respect to velocity, amplitude, and duration were used to separately deflect each whisker, usually in the unit's best direction, and the time interval between successive whisker deflections was varied, usually in steps of 0 (both whiskers together), 10 , $20,50,100$, and 1,000 ms. Each combination of stimuli was delivered a minimum of 10 times, and individual stimulus runs were separated by at least $3.5 \mathrm{~s}$. $\Lambda \mathrm{t}$ each time interval the sequence of whisker deflections was then reversed so that first whisker 1 preceded whisker 2 , and then in the next series, whisker 2 preceded whisker 1 . Each whisker was also stimulated alone to obtain a base-line measure of the unit's response to the individual whiskers deflected one at a time. In later experiments, the computer was used to generate these stimulus combinations in a randomized format.

\section{Data analysis}

The data were analyzed to determine quantitatively the effect of the first vibrissal deflection (the conditioning stimulus) on the response of the unit to displacement of the second deflected whisker (the test stimulus). For each conditioning-test combination, the mean number of spikes (for 10 stimulus presentations) elicited by the second deflection was divided by the mean discharge of the unit to deflections of the second deflected whisker by itself. A value $<1.0$ thus signifies a proportional reduction in the cell's discharges to displacements of the sec- 
ond deflected whisker (i.e., response suppression), and a value $>1.0$ indicates a response greater than that evoked by the test stimulus alone (i.e., facilitation). Most cells displayed predominantly rapidly adapting profiles, and therefore only the response to the initial displacement of the hair from its resting state to its deflected position was analyzed. The duration of the time epoch from which spike count functions were derived was determined by examining peristimulus time histograms (PSTs) constructed from the neuron's responses to 10 presentations of the test stimulus alone. The duration of a cell's response was typically 5-15 ms. Consequently, when the interdeflection interval was 10 ms, responses to conditioning and test stimuli occasionally overlapped in time. In these cases the contribution of the first (conditioning) whisker deflection was eliminated from the two-whisker (combined) response profile (see Ref. 12). To do this the latter part of the cell's response to the conditioning stimulus alone (i.e., starting at $+10 \mathrm{~ms}$ from its onset) was subtracted from that portion of the combined profile that contained the test response. The result was then divided by the cell's response to the second deflected whisker by itself (see Fig. 1 below). When both conditioning and test stimuli were presented simultaneously, that is, at 0 -ms intervals, the observed response was divided by the sum of the responses to each stimulus alone. A value of $<1.0$ indicates an observed response that is proportionally smaller than expected from a simple summation of the two "alone" responses.

\section{RESULTS}

Data were obtained from 16 animals in which a total of 124 single cortical units were examined for their responses to multiwhisker stimuli. Results show that a principal effect of a vibrissal deflection is to reduce cortical unit discharges to subsequent deflections of a second, nearby whisker. This is shown in Fig. 1, which also illustrates the basic experimental

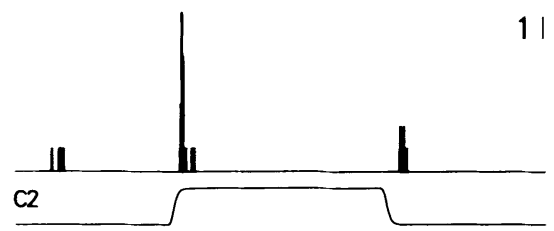

11

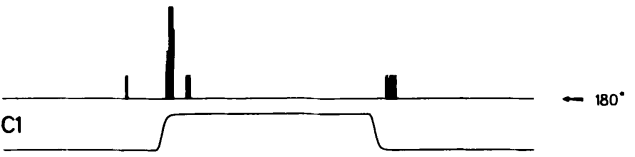

$90^{\circ}$

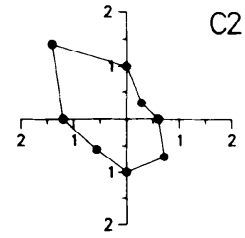

$\mathrm{C} 2$
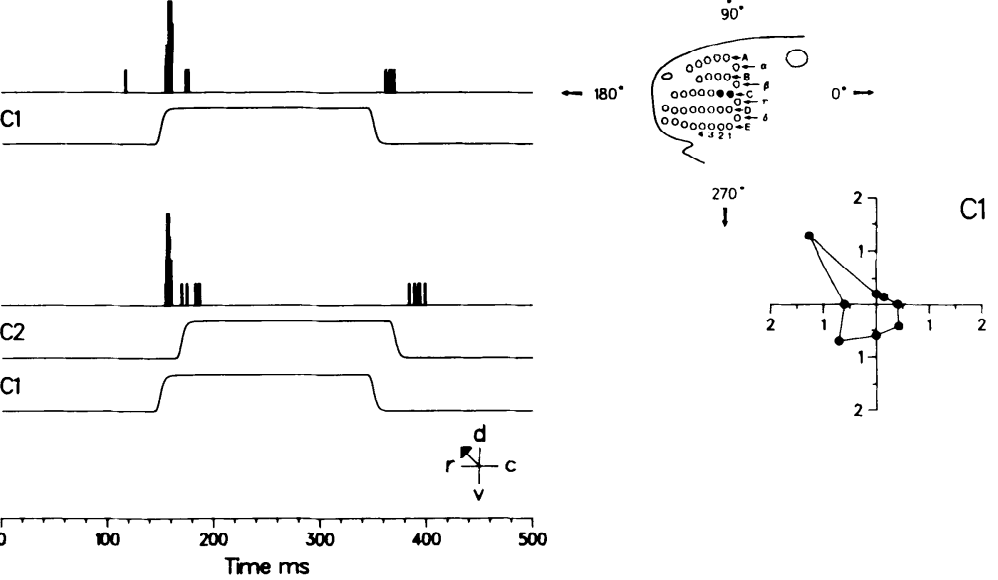

FIG. 1. Response suppression in a cortical vibrissa unit. Polar plots illustrate angular sensitivity of this cell determined by separately deflecting whiskers $\mathrm{C} 2$ and $\mathrm{Cl}$ at 8 different angles. Whisker nomenclature and polar plot orientation is shown by the figurine where $\mathrm{C} 1$ and $\mathrm{C} 2$ are indicated by filled circles. Distance from the origin represents mean spikes per stimulus. Peristimulus time histograms (PSTs) show unit responses to separate deflections of C2 and C1 and to combined deflections in which movement of $\mathrm{C} 1$ precedes that of $\mathrm{C} 2$ by $20 \mathrm{~ms}$. The hairs were deflected in an up-andforward angle (i.e., at $135^{\circ}$ ) as indicated by the "weathervane": c, caudal; r, rostral; d, dorsal; v, ventral. Analog representations of the hair displacements are shown below each PST. In these and all subsequent PSTs, data represent the accumulated response to 10 stimulus presentations, and the vertical bar in the upper right indicates 1 spike per bin. Bin width $=1 \mathrm{~ms}$. Note that a preceding deflection of $\mathrm{Cl}$ strongly suppresses the cell's response to $\mathrm{C} 2$ deflections: This unit was recorded $684 \mu \mathrm{m}$ below the pial surface. 
paradigm and the analysis of the spike data. This cell had an excitatory receptive field that included whiskers $\mathrm{C} 1$ and $\mathrm{C} 2$, and as shown by the polar plots it was most responsive to stimulation of either of these whiskers when they were displaced at a $135^{\circ}$ angle (up-andforward) relative to the horizontal alignment of the row-C vibrissac. The unit's accumulated responses to 10 deflections of each individual vibrissa are shown in the PSTs. In each case the stimulus consisted of a 1-mm displacement in an up-and-forward direction (indicated by the weathervane).

As expected from the polar plots, the cell responded vigorously to the initial movement of either hair (i.e., at $135^{\circ}$ ) and minimally to the hair's return from the deflected state (i.e., at $315^{\circ}$ ). In the PST at the bottom the two whiskers were moved in combination so that displacement of $\mathrm{Cl}$ preceded by $20 \mathrm{~ms}$ an identical movement of $\mathrm{C} 2$. A strong discharge is observed in response to the first deflected whisker, $\mathrm{C} 1$, but only a few spikes occur during the period within which a $\mathrm{C} 2$ response is expected. The mean number of discharges that occurred during this latter period was calculated from the 10 individual spike trains and found to be 0.40 with SD 0.52 . By comparison the average response of the unit to deflections of C2 alone (see upper PST) was 2.0 with SD 0.94 . Since two of the spikes in the combined response could tentatively be attributable to the secondary discharge of the cell to $\mathrm{Cl}$ alone (see METHODS), the preceding deflection of $\mathrm{Cl}$ had the effect of reducing the $\mathrm{C} 2$ response to $10 \%$ of its control value [i.e., $(4-2) \div 20=$ $0.10]$.

Qualitatively similar interactions were observed for every cortical neuron examined in this study. As will be described below, the strength of these interactions depended on the time interval between the whisker deflections and on certain spatial features of the multiwhisker stimulus. In the present report a decrement in unit discharges subsequent to a vibrissal deflection will be referred to as response suppression or response inhibition; the latter term is used for convenience of discourse and should not be taken to necessarily imply the nature of the underlying integrative mechanisms.

\section{Time course}

The time course of multiwhisker integration is illustrated in Fig. 2. These histograms show the responses of a second cortical neuron to stimulation of $\mathrm{C} 2$ alone (upper left PST) and to paired displacements of $\mathrm{C} 3$ and $\mathrm{C} 2$ at seven interdeflection intervals. This unit responded maximally to single deflections of C2 (2.4 spikes/stimulus) and less vigorously to $\mathrm{C} 3(0.8$ spikes/stimulus). A preceding deflection of C3 reduced the cell's response to subsequent deflections of $\mathrm{C} 2$ in a time-dependent fashion. For example the response to $\mathrm{C} 2$ is minimal with interdeflection intervals of $\leqslant 10 \mathrm{~ms}$, and it returns progressively toward control levels as the time separating the deflections increases. Some interaction also occurs when the two whiskers are deflected simultaneously (i.e., at $0 \mathrm{~ms}$ ), as the response in this case ( 1.8 spikes/ stimulus) is smaller than would be expected if the two alone responses summated to produce a response equal to the sum of the conditioning and test stimuli presented alone. This response, however, is only $25 \%$ smaller than that to deflections of C2 alone. Separating the displacements by 2 ms causes a similar decrement in the size of the overall response ( 1.8 spikes/ stimulus) that is more temporally dispersed.

Quantitative data from this cell and 18 other cortical units are shown in Fig. 3 as dotted lines. These graphs plot the change in the test response as a function of the time separating the first (conditioning) and second (test) deflections in the two-whisker stimulation paradigm. As described above, a value of 1.0 indicates a test response equivalent to that elicited by stimulation of the second deflected whisker by itself, and a value $<1.0$ indicates a proportional reduction in the cell's response. Data in Fig. 3 were computed for stimulus onsets only, and the abscissa represents the time interval (i.e., interdeflection interval) between the start of the conditioning stimulus and the start of the test stimulus. These graphs illustrate several important features of the temporal integration of multiwhisker inputs. First, the responsiveness of cortical vibrissa units is substantially reduced following displacements of a nearby whisker. As a general rule, facilitation was observed less often than inhibition, but this depended to a large extent on certain spatial aspects of the multiwhisker stimulus (see below). Second, response inhibition is greatest at short interdeflection intervals (i.e., 10 and $20 \mathrm{~ms}$ ) and decreases with longer intervals. The responsiveness of most cells returns to at least $75 \%$ of control values during the $100 \mathrm{~ms}$ following a vibrissal stim- 

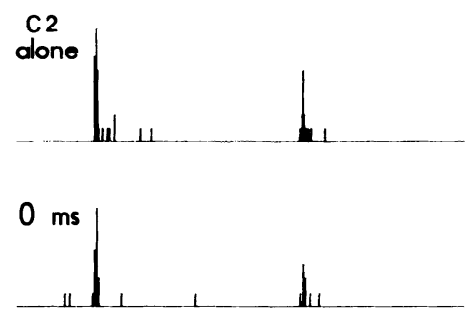

$2 \mathrm{~ms}$

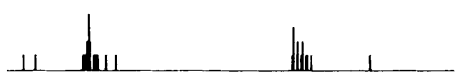

$5 \mathrm{~ms}$
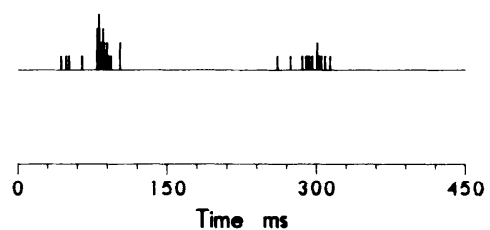

$10 \mathrm{~ms}$

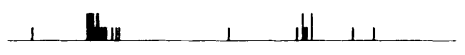

$20 \mathrm{~ms}$

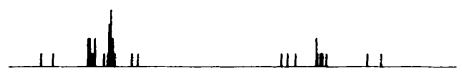

$50 \mathrm{~ms}$
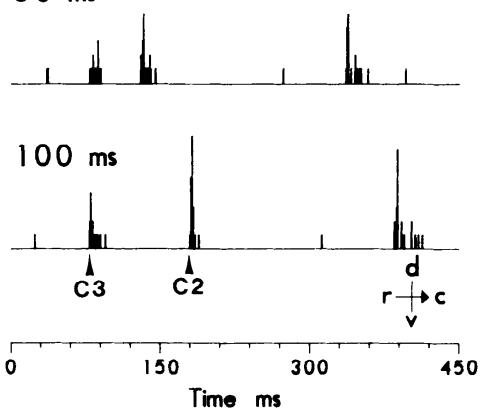

FIG. 2. Time course of neuronal integration of multiwhisker stimuli. PSTs show unit responses to deflections of $\mathrm{C} 2$ alone (upper left) and to paired displacements of $\mathrm{C} 3$ and C2. Displacements of $\mathrm{C} 2$ follow those of $\mathrm{C} 3$ by the indicated time intervals, and the peristimulus time histograms (PSTs) are aligned with respect to the onset of the C3 deflections that occur at $\sim t=75 \mathrm{~ms}$ (see time scales at the bottom). The cell's response to C3 alone can be seen in the 20-, 50-, and 100-ms PSTs where the responses to each whisker are clearly separated in time. The responses to the initial displacement of $\mathrm{C} 3$ and $\mathrm{C} 2$ are labeled in the 100-ms panel. These data show that response suppression is greatest at short interdeflection intervals and declines progressively during the $100 \mathrm{~ms}$ following a vibrissal deflection. Note also that a strong C2 "off" response (to the return of C2 from its deflected position) can be seen in the 50- and 100-ms panels (stimulus duration $=200 \mathrm{~ms}$ ). This unit was recorded $775 \mu \mathrm{m}$ below the pial surface.

ulus, and by $1,000 \mathrm{~ms}$ (data not shown) cells were observed to respond within their control range. Third, the strength of inhibition is quite variable at 50-ms intervals. In some cases responses at this interval were observed to actually be greater than those at $100 \mathrm{~ms}$, and occasionally facilitation (i.e., responses greater than control levels) was observed with interdeflection intervals of $50 \mathrm{~ms}$ but not 20 or 100 ms. In fact, unit discharges could sometimes be elicited by deflecting normally ineffective whiskers $50 \mathrm{~ms}$ after stimulating an effective one. Fourth, as noted above, it appears that inhibition develops rapidly but not necessarily immediately following a vibrissal deflection. With simultaneous whisker deflections, the responses of eight of these cells were larger than their responses to either of the individual whiskers deflected alone, and in one case the combined response equaled the sum of the two alone responses (i.e., a value of 1.0). The remaining units displayed responses that were less vigorous than the larger of the two alone responses but greater than the smallest alone response. Since suprathreshold stimuli were used for both whisker deflections, these findings could reflect occlusion of inputs from two overlapping and maximally activated neural pools. Finally, data not shown revealed that the time course of response suppression to stimulus offsets is similar to that illustrated in Fig. 3 for stimulus onsets; typically, however, the magnitude of response suppression is less in the former case than in the latter (see below).

\section{First-order neurons}

Careful observation of the whiskers, using a dissecting microscope, revealed that displacement of a whisker causes a slight deformation of adjacent regions of the mystacial pad and corresponding low-amplitude movements of nearby vibrissae. Moreover, the displacement of a nearby whisker relative to its hair follicle is increased when its distal end is held in place by attachment to a mechanical stimulator. To assess the extent to which such mechanical interactions in the periphery could 


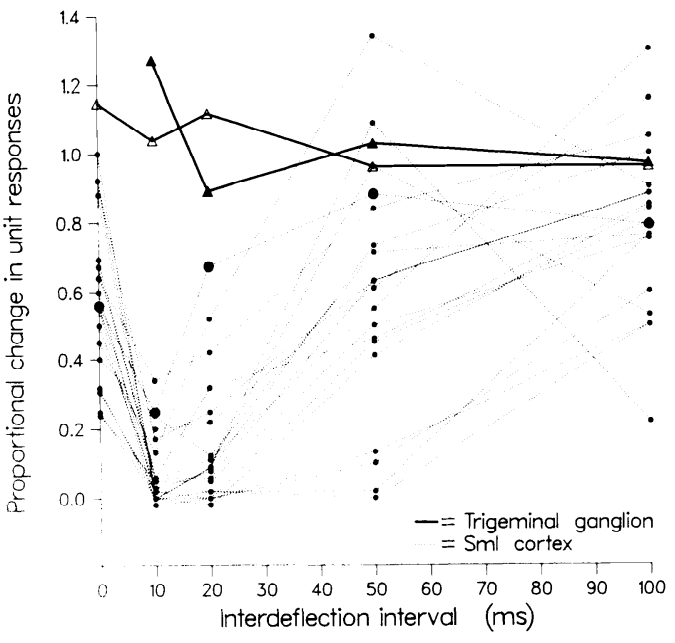

FIG. 3. Quantitative data showing the time course of response suppression in the cortex and in the trigeminal ganglion. Graphs plot the proportional change in unit responsiveness as a function of the interdeflection time interval for 18 cortical neurons (dashed lines) and 2 1storder neurons (solid lines). Data are computed for stimulus onsets only (i.e., initial movements of the whiskers from their neutral position). For each data point, the mean discharge in response to the 2 nd of a 2 -whisker stimulus is divided by the mean discharge of that unit to deflection of the 2 nd deflected whisker by itself. For intervals of 0 $\mathrm{ms}$, the observed response was divided by the sum of the 2 "alone" responses (see METHODS). A value $<1.0$ represents response suppression. Large, filled circles are data from the cortical cell of Fig. 2, and filled triangles are data from the 1st-order neuron of Fig. 4 below.

account for integrative phenomena observed in the cortex, 26 units that were recorded in the trigeminal ganglion of four barbiturateanesthetized rats were examined for their responses to multiwhisker stimulation. Data from a low-threshold, slowly adapting neuron are illustrated in Fig. 4. The topmost PST shows the cell's response to $1-\mathrm{mm}$ displacements of whisker D2. The second panel demonstrates that a small, transient response can also be elicited from this cell by deflecting the immediately adjacent hair, D3, while the D2 hair is held at its neutral position by a stimulator. This D3 response could only be evoked by using deflections of D3 large enough to deform the skin around the D2 follicle, thus causing the D2 hair to bend, and is therefore most likely due to mechanical spread of the stimulus energy through the mystacial pad. The remaining PSTs in Fig. 4 show the effect of stimulating these two whiskers in combination so that displacement of D3 precedes that of $\mathrm{D} 2$ by variable intervals, and it can be seen that there is virtually no effect of $\mathrm{D} 3$ on the $\mathrm{D} 2$ response. Quantitative data from this

\section{D3 Precedes D2}
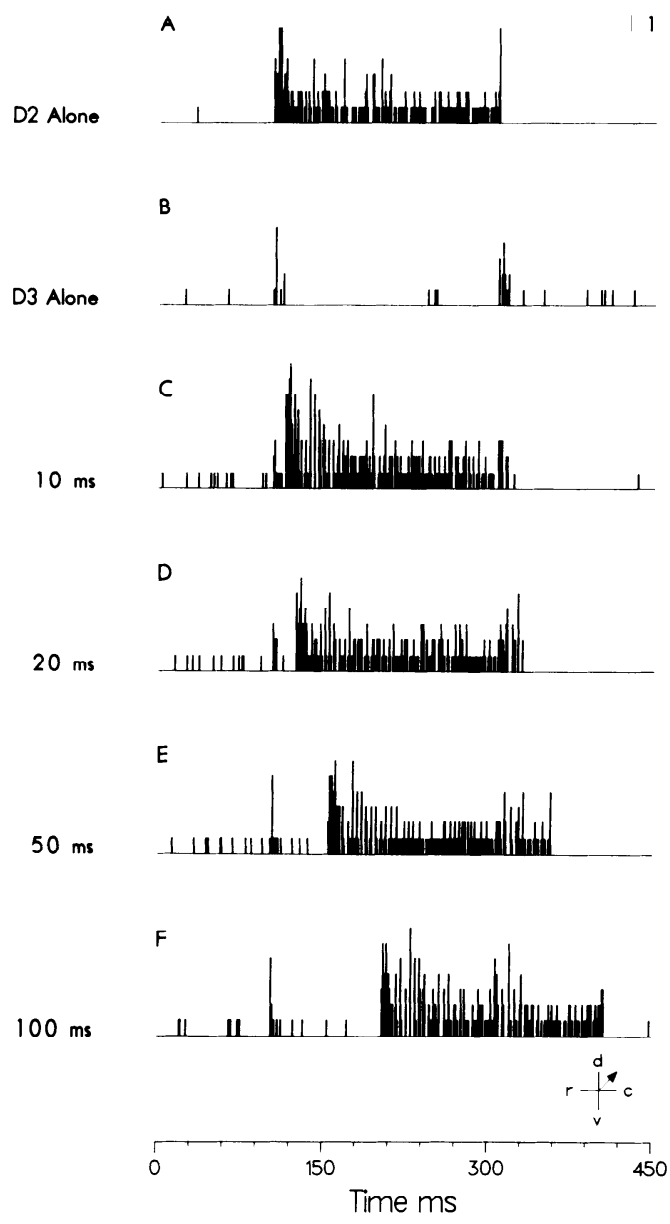

FIG. 4. Effects of multiwhisker stimulation on a cell in the trigeminal ganglion. This neuron responded in a slowly adapting fashion to displacements of D2 $(A)$. A smaller, transient response could also be elicited by deflection of D3 $(B)$ and was largest when D2 was held in place by attachment to a 2 nd stimulator (see text). $C-F$ shows that a preceding displacement of $\mathrm{D} 3$ produces little or no change in the D2 response regardless of the interdeflection interval. The apparent increase in spontaneous discharge between $A$ and $B-E$ is due to slight off-axis positioning of the D2 stimulator that was detached and reattached several times. The sensitivity of this neuron to small displacements of D2 is illustrated by the rythmic pattern of discharge during the early phase of the stimulus plateau in $C-F$; this corresponds to "ringing" of the probe tip of $<5 \mu \mathrm{m}$, as determined by simultaneous monitoring using a phototransistor circuit (see Ref. 54). 
cell and a rapidly adapting peripheral neuron are shown in Fig. 3 as triangles and solid lines. Whereas data from a few of the most sensitive afferents suggest that some interactions may occur as a result of mechanical spread of the stimulus from one follicle to the next, these effects were rather subtle and quite unlike those observed at the cortical level.

\section{Spatial aspects}

Data in Figs. 2 and 3 were chosen to illustrate the nature and time course of response suppression observed under some but not all multiwhisker stimulus conditions. Whereas all cortical neurons studied displayed response suppression, the presence and degree of this suppression depended in part on which whiskers in a receptive field were stimulated and on the spatial order of the multiwhisker displacements, that is, which whisker was deflected first. This is illustrated in the PSTs in
Fig. 5. As shown in the topmost PSTs, this neuron responded maximally to deflections of B1 (left) and somewhat less vigorously to B2 (right). The remaining histograms at the left show that a preceding deflection of $\mathrm{B} 1$ inhibits the unit's response to subsequent deflections of B2 in a time-dependent fashion. Qualitatively similar effects are obtained when B2 precedes B1 (right-hand column), though here the suppression of the response to the second deflected whisker is not as great. Of particular interest is the cell's behavior at 10 -ms interdeflection intervals. When $\mathrm{B} 1$ is deflected first, the response to the second deflection is completely abolished, whereas when B2 is deflected first some discharges to the second deflected whisker are observed, and the total response is greater than that to deflections of either B1 or B2 alone. The overall response of this cell to these whiskers' contact with an object moving through the vibrissal field might therefore

\section{B1 Precedes B2}
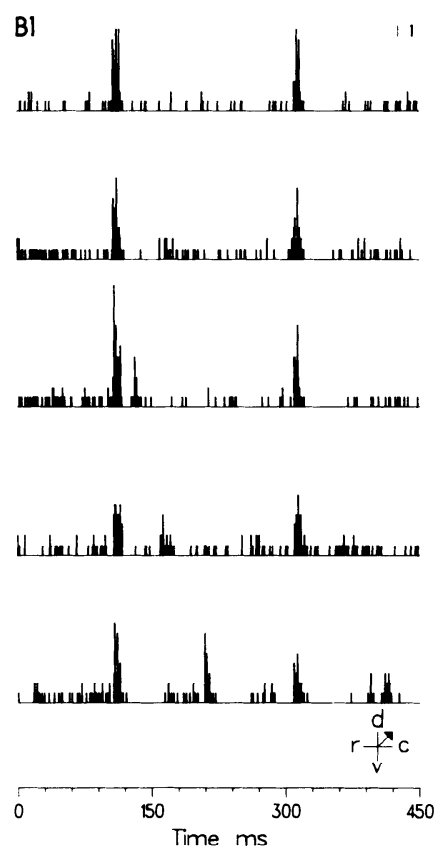

B2 Precedes B1

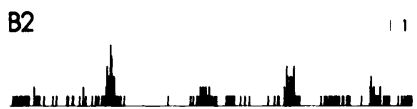

$10 \mathrm{~ms}$

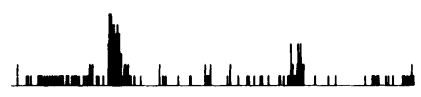

$20 \mathrm{~ms}$

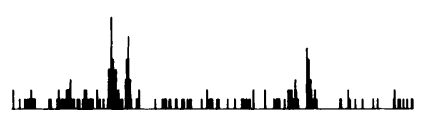

$50 \mathrm{~ms}$
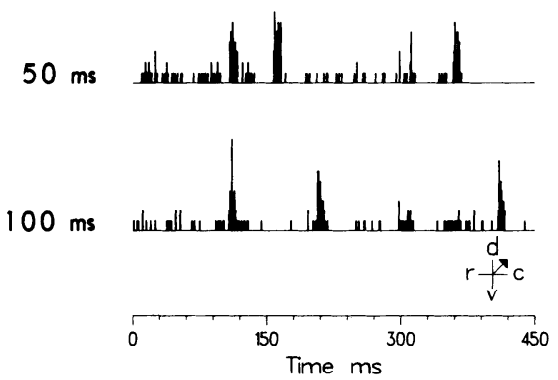

FIG. 5. Importance of spatial order in determining unit responses to combined whisker deflections. Peristimulus time histograms (PSTs) show this unit's response to deflections of B1 and B2 alone (top panels in left and right columns) and to paired displacements of these whiskers at 4 interdeflection intervals. PSTs are aligned with respect to the onset of the 1st deflected vibrissa that occurs at $\sim t=100 \mathrm{~ms}$. Note the differences in discharge patterns that result from a reversal of the spatial order of the deflections, especially for stimulus onsets at 10 -ms intervals. A period of reduced activity can be seen during the $100 \mathrm{~ms}$ following the B2 alone stimulus; this parallels the time course of response suppression when the hairs are deflected sequentially. This unit was recorded $1,355 \mu \mathrm{m}$ below the pial surface. 
depend on the object's velocity (i.e., the interdeflection interval) and on whether its trajectory caused $\mathrm{B} 1$ and $\mathrm{B} 2$ to be displaced in a rostral-to-caudal sequence or in a caudal-torostral one.

Figure 6 illustrates that stimulating different combinations of whiskers also affects the responses of cortical neurons to multiwhisker stimuli. This cell responded best to deflections of $\mathrm{C} 2$ and less vigorously to deflections of adjacent whiskers $\mathrm{C} 1$ and $\mathrm{C} 3$. A preceding displacement of C3 (left panel) substantially reduced the cell's response to subsequent displacements of $\mathrm{C} 2$ at interdeflection intervals of 10,20 , and $100 \mathrm{~ms}$. Note that response suppression is less pronounced at 50 -ms intervals, and in fact a small "off" response associated with the return movement of $\mathrm{C} 2$ to its neutral position can be seen (see above). By contrast, combined deflections of $\mathrm{Cl}$ fol- lowed by $\mathrm{C} 2$ elicit two distinct response peaks to stimulus onsets that are separated by appropriate $10-, 20-, 50-$, or $100-$ ms intervals. At each condition-test interval, including $0 \mathrm{~ms}$, the total response to stimulus onsets was larger with the $\mathrm{C} 1-\mathrm{C} 2$ combination than with the C3-C2 combination. This reflects both the magnitude of the response to the first ( $\mathrm{Cl}$ vs. C3) deflection and the degree of suppression of the second $(\mathrm{C} 2)$ response. The overall response of the cell to an object moving through the vibrissal field might therefore be considerably larger with a caudal-to-rostral trajectory than with a rostral-to-caudal one.

\section{Receptive-field properties and columnar organization}

There was a columnar pattern to the distribution of excitation and inhibition within cortical receptive fields. All driveable cells en-

\section{C3 Precedes C2}

\section{Cl Precedes C2}
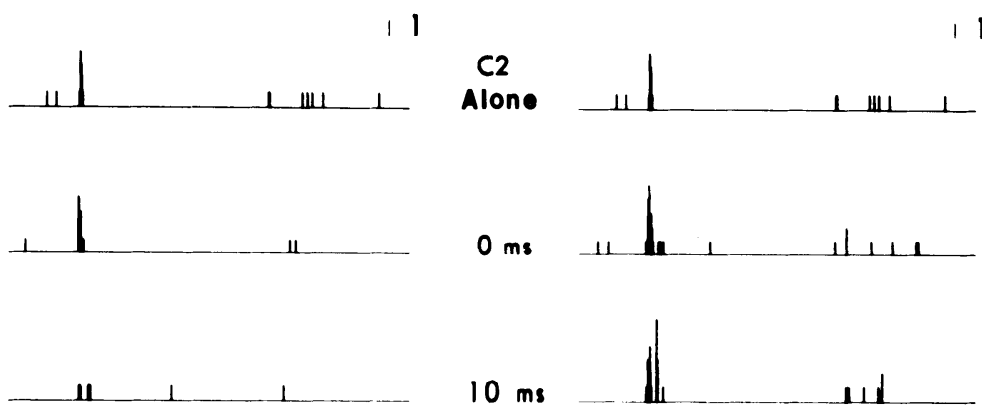

$10 \mathrm{~ms}$
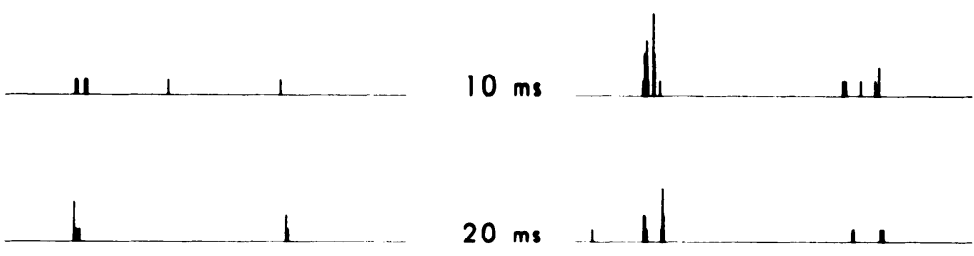

20
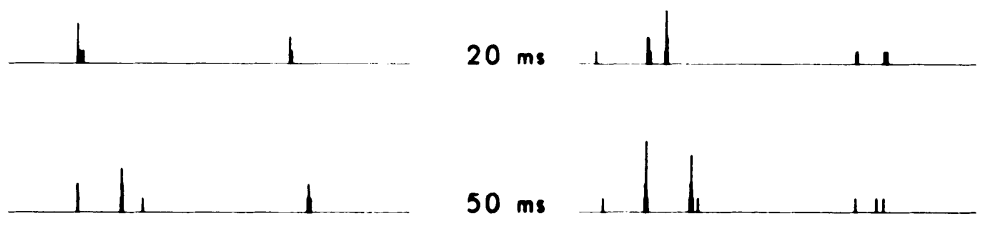

$50 \mathrm{~ms}$
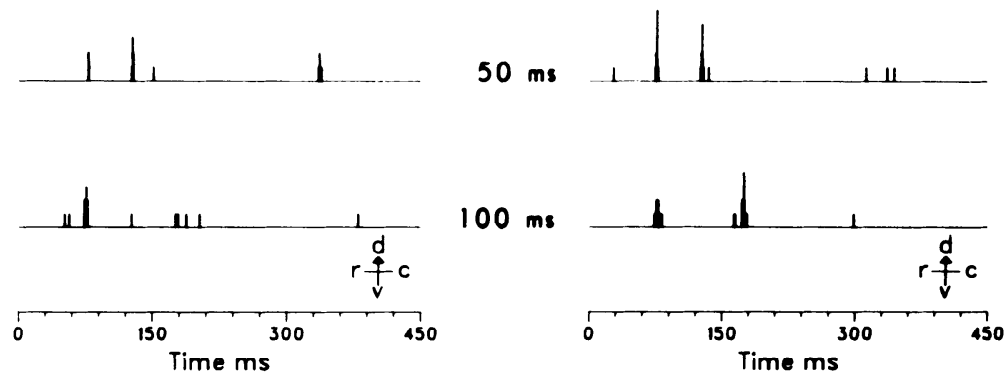

FIG. 6. Importance of whisker combination in determining unit responses to combined whisker deflections. Peristimulus time histograms show this cell's response to deflections of $\mathrm{C} 2$ alone (top of each column) and to paired $\mathrm{dc}$ - lections of C3-C2 and $\mathrm{C} 1-\mathrm{C} 2$. Other conventions as in Fig. 5. Note the absence of significant response suppression when $\mathrm{C} 1$ precedes $\mathrm{C} 2$. Quantitative data for this cell are plotted in Fig. $7 D$. 
countered during a given electrode penetration were maximally activated by one particular vibrissa, the columnar or principal whisker (PW) of the penetration. Other neighboring whiskers could also activate cells, but the strength of their excitation was usually less than that of the PW (see also Ref. 53). Similarly when whiskers were deflected in paired combinations, the strongest inhibitory effects were usually elicited by the columnar whisker; other, nearby vibrissae elicited variable amounts of inhibition. For example in the cases illustrated in Figs. 5 and 6, the PW's were $\mathrm{B} 1$ and $\mathrm{C} 2$, respectively.

The relationship between the PW and nonPW whiskers is illustrated further in Fig. 7. In each panel, bar graphs indicate excitatory components of the receptive field, and the response-suppression curves illustrate inhibitory areas. The height of the bars represents the magnitude of the responses to deflections of the indicated whiskers. Inhibitory effects exerted by the PW (i.e., when the PW is the conditioning stimulus) are shown by curves with solid lines, whereas inhibitory influences of adjacent whiskers on the cell's response to subsequent deflcctions of the PW are shown as dashed lines (see Fig. 7 legend). Figure 7, $A$ and $B$, depicts receptive fields in which strong inhibitory effects were exerted equivalently by both the PW and non-PW vibrissae. Within each panel there are marked similarities in the response suppression curves obtained from different whisker pairings, but the recovery
A

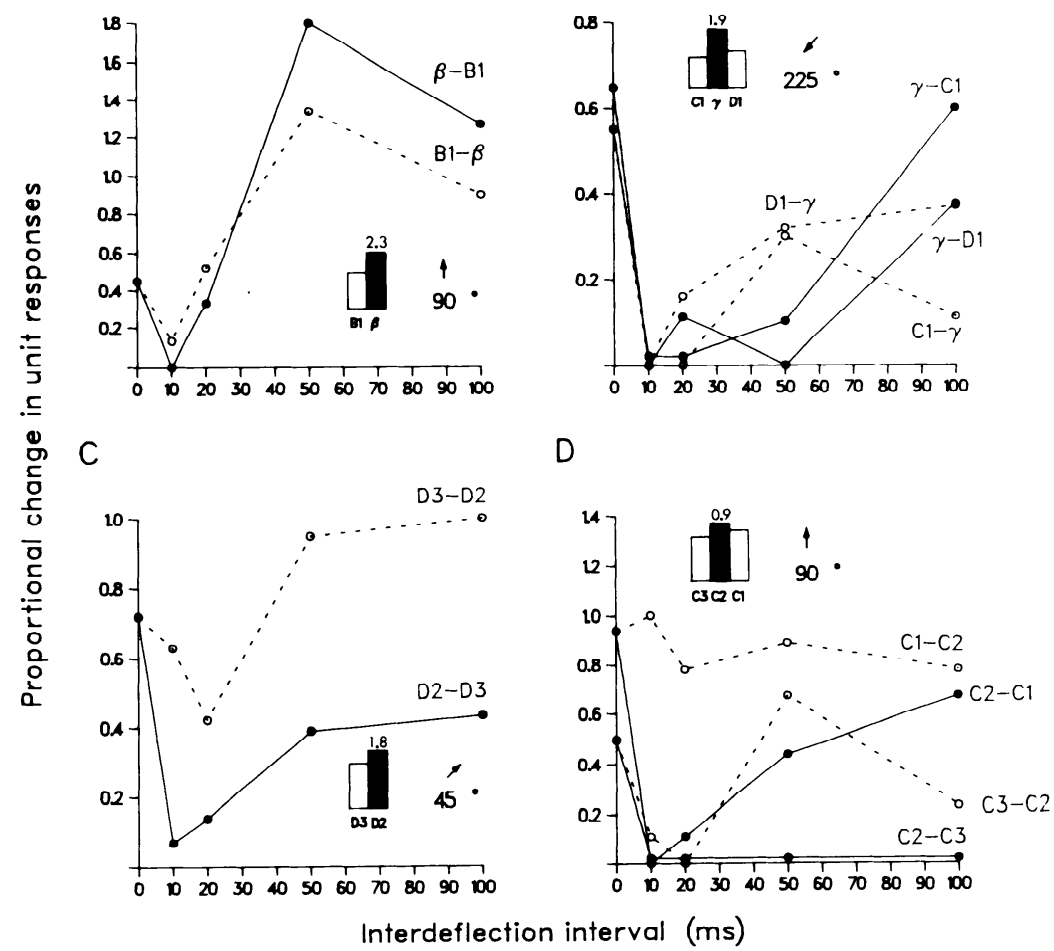

FIG. 7. Relationship between the principal whisker and adjacent vibrissae. In $A-D$ excitatory components of a cell's receptive field are shown as bar graphs in which the height of each bar represents the magnitude of the response elicited by deflections of the indicated whisker stimulated alone. The response elicited by the principal whisker is indicated by mean values (spikes per stimulus) above the solid bars. The angle in which the whiskers were moved is indicated in each panel. Inhibitory components are illustrated by the graphs. Effects of the principal whisker (PW) are shown by solid lines; effects of adjacent whiskers on responses to PW deflections are shown by dashed lines. The stimulus sequence from which response suppression curves were derived is indicated for each graph (e.g., D3-D2, D3 displacements precede D2 displacements). In $A$ and $B$ inhibitory influences are exerted equivalently by PW and non-PW whiskers. In $C$ and $D$ inhibitory effects of an adjacent whisker are clearly less than those of the PW. Depth of each unit based on microdrive readings: $A: 391 \mu \mathrm{m} ; B: 978 \mu \mathrm{m} ; C: 771 \mu \mathrm{m} ; D: 1,455 \mu \mathrm{m}$. 
times of these two neurons are quite different from each other. In particular both whisker combinations in Fig. $7 A$ show response facilitation to the second deflected whisker at 50 $\mathrm{ms}$, whereas none of the test responses in $B$ attain control levels, even at 100-ms intervals. By contrast, Fig. 7, $C$ and $D$, illustrates receptive fields in which there are substantial differences in the strength of response suppression elicited by PW and non-PW whiskers. In both cases the PW produces the strongest inhibitory effects. Data in Fig. $7 D$ are from the cell illustrated in Fig. 6, and the graphs indicate quantitatively that $\mathrm{C} 3$ strongly suppresses the PW response, whereas the other immediately adjacent whisker (C1) has only a small inhibitory effect.

\section{Symmetrical and asymmetrical receptive fields}

The data in Fig. 7 demonstrate how cortical vibrissa units could differ in terms of the spatial organization of excitatory and inhibitory components of their receptive fields. An important variable here appears to be the relative contributions of non-PW vibrissae. This is illustrated further in Fig. 8, which shows data for eight units obtained by deflecting the PW in combination with its two immediately adjacent neighbors in the same horizontal row. As in Fig. 7, bar histograms indicate the excitatory receptive field; the graphs plot the effects of a preceding deflection of each of the adjacent whiskers on the cell's response to a subsequent movement of the PW. Figure $8 A$ depicts a multiple-whisker receptive field with an excitatory focus at $\mathrm{C} 2$ (the PW) and adjacent excitatory regions of approximately equal influence ( $\mathrm{Cl}$ and $\mathrm{C} 3$ ); each of these adjacent whiskers exerts equivalent inhibitory effects on the cell's response to the PW, which in turn strongly inhibits responses to both of them (data not shown). Figure $8 H$ on the other hand shows a cell with a sharply focused excitatory receptive field $(\mathrm{C} 2)$ that is inhibited by its rostral neighbor (C3) but is relatively unaffected, or even slightly facilitated, by its caudal one (C1). Units in $C, E$, and $G$ were alike in that each was excited by only one of the PW's neighbors but are otherwise dissimilar in that the unit in $C$ was equally inhibited by both adjacent whiskers, whereas in $G$, and to a lesser extent in $E$, one adjacent whisker strongly inhibits the cell's response to the PW while the

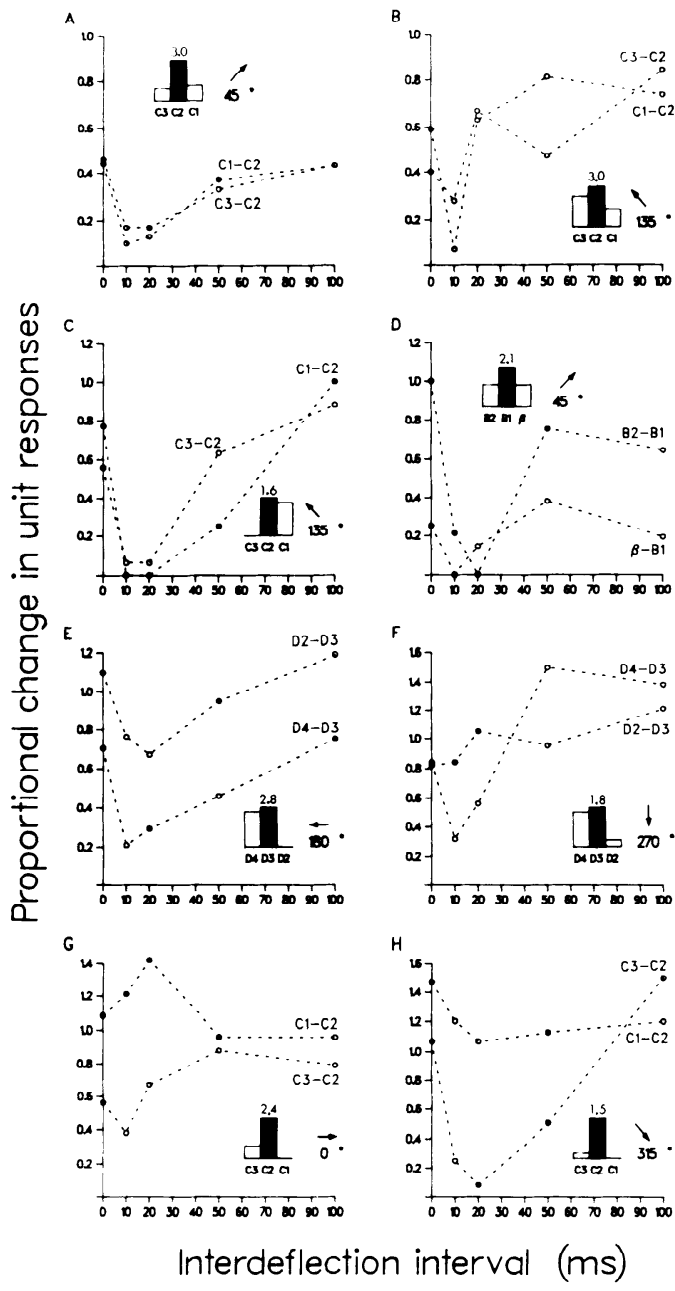

FIG. 8. Symmetrical and asymmetrical receptive fields. $A-H$ shows excitatory and inhibitory components of vibrissal fields in a format similar to that used in Fig. 7 except that the inhibitory effects of the principal whisker (PW) have been omitted. $A-D$ illustrate receptive fields that have equivalent inhibitory zones on each side of the PW. In $E-I I$ there is an asymmetrical distribution of inhibition within the receptive field. Depth of each unit: $A: 283 \mu \mathrm{m} ; B: 913 \mu \mathrm{m} ; C: \quad 684 \mu \mathrm{m} ; D: 530 \mu \mathrm{m}$; $E: \quad 1,591 \mu \mathrm{m} ; F: 589 \mu \mathrm{m} ; G: 775 \mu \mathrm{m} ; H: 643 \mu \mathrm{m}$. There was a tendency for asymmetrical units to be found mainly in the deeper aspects of the cortex although this relationship is not indicated by the data in this figure (see text).

other's effect is slightly facilitatory $(G)$ or only minimally inhibitory $(E)$. In all cases, the PW exerted inhibitory effects on adjacent excitatory whiskers that were at least as strong as those indicated in the illustrated plots.

Whereas the material shown in Fig. 8 attests 
to the diversity of receptive-ficld organization that is observed using paired whisker stimuli, examination of these data and those from 22 similarly studied cells indicate that it is possible to distinguish among vibrissal receptive fields on the basis of the distribution of inhibitory subregions with respect to the PW. For example, the units in Fig. $8, A-D$, have symmetrically distributed inhibitory zones in that both adjacent whiskers exert roughly equivalent inhibitory effects on the responses of the cells to deflections of the PW. By contrast, markedly different effects of the two adjacent whiskers are clearly evident in Fig. $8, E-H$, and in Fig. 7D. Differences are greatest at 10and 20-ms interdeflection intervals where response suppression, when present, is most pronounced. Student's $t$ tests were used to compare the effects of adjacent rostral and caudal whiskers on the cell's responses to the $\mathrm{PW}$. A receptive field was classified as asymmetrical if the responses to the PW in each case differed from one another at the 0.05 level (two-tail). Table 1 summarizes the findings and shows the proportion of asymmetrical receptive fields in the middle, superficial, and deep aspects of the cortex. Thirty percent of the cells had an asymmetrical distribution of inhibition within their receptive fields. Interestingly, most of these were recorded in the deeper aspects of the cortex where the majority of the receptive fields $(60 \%)$ were classified as asymmetrical. By contrast, receptive fields in the middle and superficial aspects of the cortex were predominantly of the symmetrical variety.

\section{Angular sensitivity}

The response of many vibrissa units in the SI cortex, as in the periphery (see Fig. 2 in Ref. 54), depends in large measure on the angular direction in which a whisker is deflected. As a general procedure, multiwhisker stimuli

TABLE 1. Inhibitory receptive-field asymmetries and cortical depth

\begin{tabular}{cccc}
\hline $\begin{array}{c}\text { Microdrive } \\
\text { Reading, } \mu \mathrm{m}\end{array}$ & $\begin{array}{c}\text { Sym- } \\
\text { metrical }\end{array}$ & $\begin{array}{c}\text { Asym- } \\
\text { metrical }\end{array}$ & $\begin{array}{c}\text { \% Asym- } \\
\text { metrical }\end{array}$ \\
\hline $0-749$ & 11 & 2 & 15 \\
$750-1,099$ & 6 & 1 & 14 \\
$1,100-2,000$ & 4 & 6 & 60 \\
Total & 21 & 9 & \\
\hline
\end{tabular}

were delivered at the cell's maximally excitatory angle, and all of the data presented above were obtained by deflecting both the PW and non-PW whiskers in the same direction. During the course of the study, however, it became apparent that deflection angle was another factor underlying the integration of multiwhisker inputs. This was evidenced by the finding that "off" response inhibition (i.e., to stimulus offsets) was often less pronounced than response suppression to stimulus onsets. For example, of 24 cases where a unit responded well to both stimulus onsets and offsets (e.g., Fig. 5), 15 cells showed less off than on response inhibition, 4 cells showed no difference, and only 5 cells showed greater response suppression to stimulus offsets than onsets. The average proportional reduction in unit responsiveness at $20-\mathrm{ms}$ condition-test intervals was 0.24 for on responses and 0.77 for off responses.

The dependence of response suppression on deflection angle is illustrated in Fig. 9, which shows angular excitatory and inhibitory zones for four of the more extensively studied cells. For each cell an angular excitatory zone was first determined by deflecting the PW randomly in different directions; this is indicated in the polar plots as solid lines and filled circles. Subsequently the PW was displaced in its preferred angular direction and was preceded 10 or $20 \mathrm{~ms}$ earlier by deflection of an adjacent whisker at different angles. The proportional change in the cell's response to the second deflected whisker (the PW) was plotted on the same polar coordinates to define an angular inhibitory zone; this is indicated by dotted lines and stippling, and here a value of 1.0 represents maximal inhibition (i.e., no response from the PW). Figure 9, $A-C$, depicts units whose angular inhibitory zones are quite similar to their angular excitatory zones. Thus for these cells inhibitory effects were greatest at the angles that elicited good excitatory responses from the PW. By contrast in Fig. 9D the inhibitory zone is clearly oriented at right angles to a narrowly tuned excitatory zone. For this unit inhibitory zones were computed separately for two adjacent whiskers (C3 and C5), which were immediately adjacent to the PW (C4), and in both cases inhibitory effects were found to be greatest at 0 and $180^{\circ}$ (for clarity of illustration only data for $\mathrm{C} 3$ are shown). 

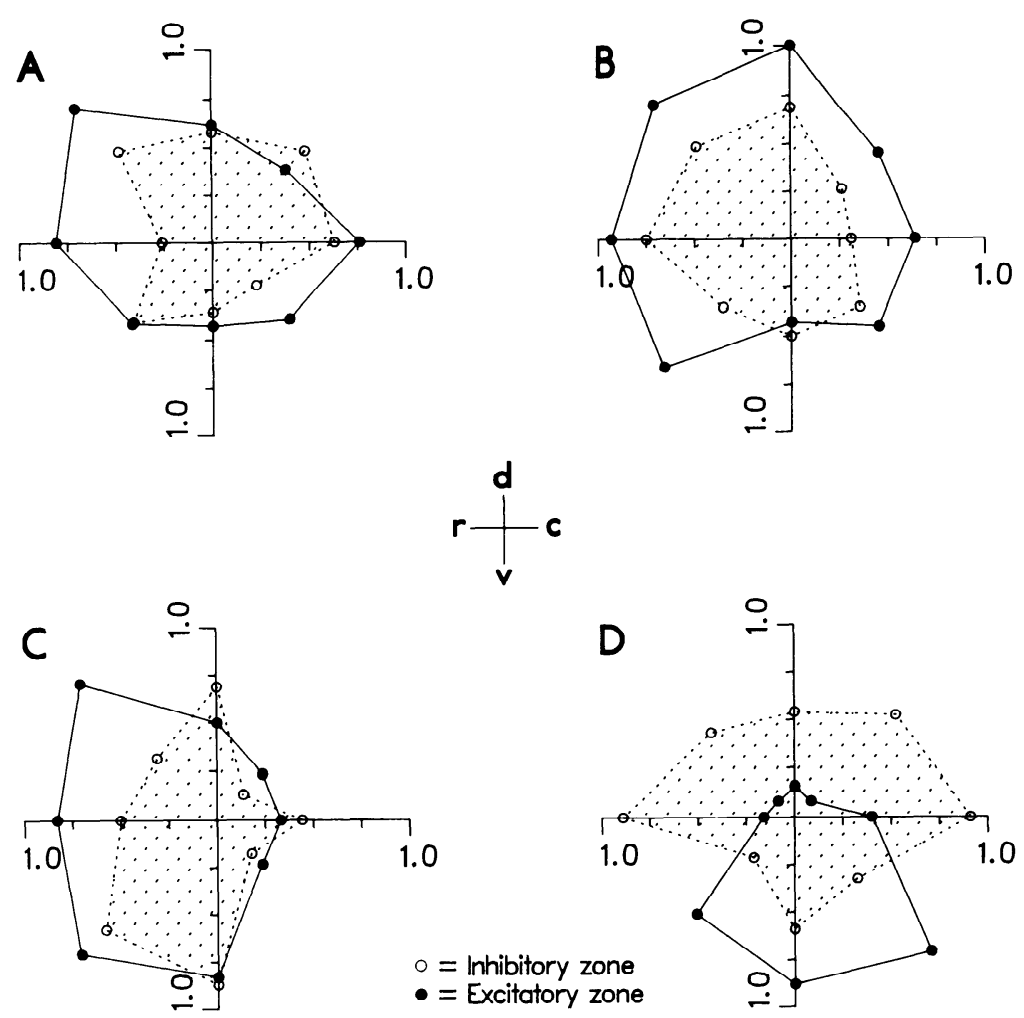

FIG. 9. Angular excitatory and inhibitory zones of 4 cortical neurons. Solid lines are polar plots showing each unit's angular sensitivity based on the mean number of its discharges to deflections of the PW in 8 different directions. Data are normalized to each cell's maximal response that is represented as 1.0 (i.e., maximal excitation), and the orientation of the polar plots is the same as in Fig. 1 (see weathervane). Dotted lines and stippling illustrate inhibitory effects of 1 adjacent whisker; here the PW was deflected in its maximally excitatory angle, preceded $20 \mathrm{~ms}$ earlier by deflections of the adjacent whisker at 8 different angles. The proportional reduction in the cell's response to deflections of the PW was plotted so that a value of 1.0 represents maximal inhibition (i.e., no PW response). Depth of each unit: $A$ : 643 $\mu \mathrm{m} ; B: 614 \mu \mathrm{m} ; C: 756 \mu \mathrm{m} ; D: 755 \mu \mathrm{m}$.

\section{Direction-selective neurons}

Data obtained in the two-whisker paradigm suggested that some cortical neurons might respond selectively to spatially patterned stimuli that mimic object movement across a fairly broad extent of the vibrissal field. To examine this possibility a third independently controllable whisker stimulator was used during the last two experiments so that whiskers could be deflected in groups of three. Data from one of these cells are illustrated in Fig. 10 . This cell was recorded $\sim 1,200 \mu$ m below the pial surface, and the PW of the electrode penetration was $\mathrm{C} 3$. In Fig. $10 \mathrm{~A}$, whiskers $\mathrm{C} 5$, $\mathrm{C} 4$, and $\mathrm{C} 3$ were sequentially displaced in a rostral-to-caudal spatial order (interdeflection interval, $20 \mathrm{~ms}$ ), but the individual hairs were moved forward, toward the front of the ani- mal. Only two small peaks, one each to C5 and $\mathrm{C} 4$, are observed in the PSTs, indicating that prior deflection of $\mathrm{C} 5$ and/or $\mathrm{C} 4$ completely suppressed the normally vigorous response of the cell to displacements of C3. In Fig. 10B, the same spatial sequence was used, but in this case the angular displacements of the hairs were directed caudally (i.e., the angular displacements parallel the spatial sequence). Under these stimulus conditions three progressively larger peaks are observed at appropriate 20 -ms intervals.

A stimulus pattern similar to the one shown in Fig. $10 B$ was employed in $C$ and $D$, except that the stimuli started with successively more caudal vibrissae. When whiskers $\mathrm{C} 4, \mathrm{C} 3$, and $\mathrm{C} 2$ are sequentially displaced, three distinct response peaks at 20 -ms intervals are again 
A

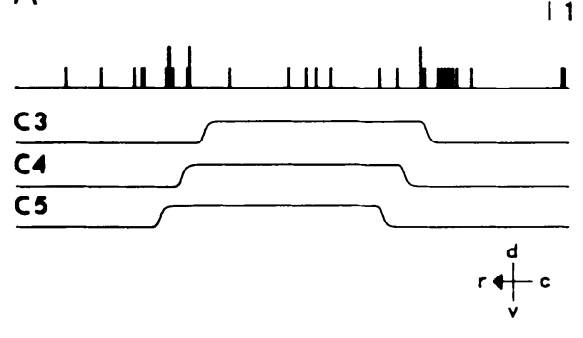

C
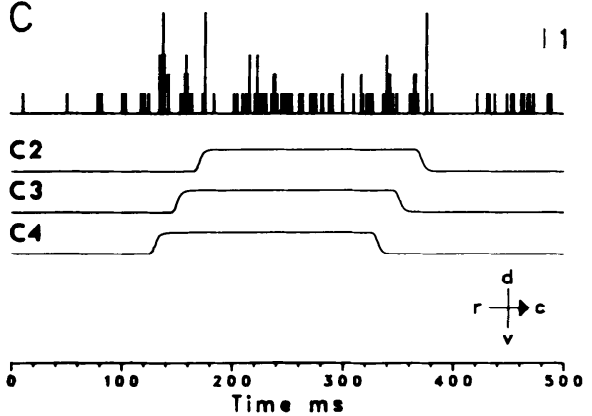

B
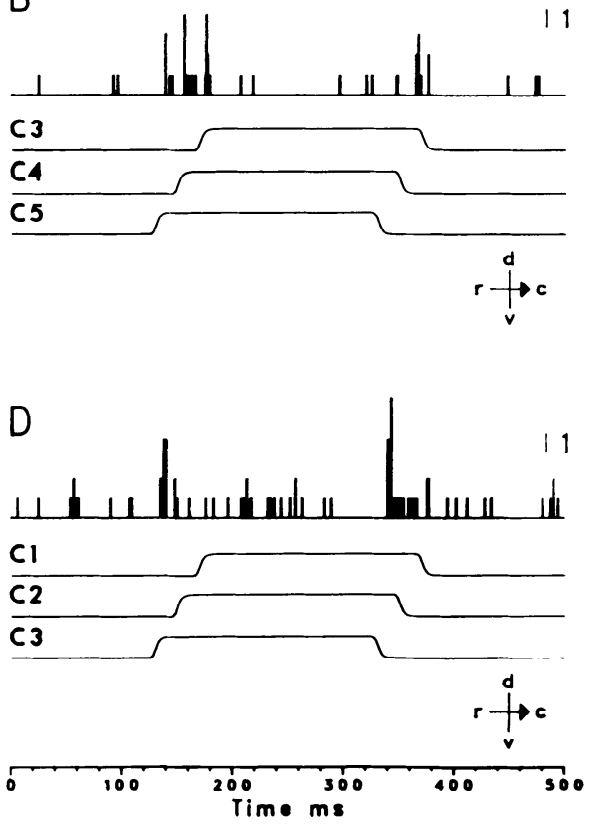

FIG. 10. Response properties of a direction-selective cell. The stimulus pattern consists of three individual whisker displacements separated by $20 \mathrm{~ms}$. In $A$, whiskers $\mathrm{C} 5, \mathrm{C} 4$, and $\mathrm{C} 3$ were deflected in a rostral-to-caudal sequence, but the individual hairs were moved forward (i.e., at $180^{\circ}$, see weathervane); only 2 small response peaks are observed. In $B$, the spatial order of the deflections parallels the angular displacements of the hairs (caudally and at $0^{\circ}$ ), and 3 progressively larger peaks are observed at intervals of $20 \mathrm{~ms}$. Data shown in $C$ and $D$ suggest that a preceding deflection of $C 4$ diminishes the suppressive influence of $C 3$ on $C 2$; note the absence of a large $C 2$ response in $D$ and the presence of a good $C 2$ response in $C$ (third peak). Also of interest is the presence of a small sustained response in $C$ that is not seen in $D$. This cell might be selectively excited by object movement in a front-to-back direction that sequentially displaces $\mathrm{C} 5-\mathrm{C} 2$. This unit was recorded $1,188 \mu \mathrm{m}$ below the pial surface.

observed. However, when the stimulus begins with $\mathrm{C} 3$, as in Fig. $10 D$, only a small response is observed for the $\mathrm{C} 2$ deflection. No response is observed for the $\mathrm{Cl}$ deflection, a whisker that did not by itself excite the cell. Comparison of Fig. 10, $C$ and $D$, is especially interesting because it suggests that a preceding deflection of $\mathrm{C} 4$ diminishes (i.e., disinhibits?) the suppressive influence of $\mathrm{C} 3$ (the $\mathrm{PW}$ ) on $\mathrm{C} 2$. Also of interest is the presence of a modest sustained component of the cell's response in Fig. $10 C$ to the maintained whisker displacements, which is not observed in $D$, even though the overall levels of pre- and poststimulus activity are comparable. Other data (not shown) demonstrated that sequential displacements of C3-C5 elicited only a single response peak (to the $\mathrm{C} 3$ deflection). Similarly, displacements at 0 or $180^{\circ}$, which originated at $\mathrm{C} 1$ or $\mathrm{C} 2$, resulted in a complete absence of an excitatory discharge (i.e., with the sequence $\mathrm{C} 1$, then $\mathrm{C} 2$, then $\mathrm{C} 3$ ) or only one peak, when $\mathrm{C} 2$ was deflected first $(\mathrm{C} 2$, then $\mathrm{C} 3$, then $\mathrm{C} 4$ ). This neuron might therefore be maximally excited by the leading edge of an object moving in a front-to-back trajectory as it sequentially displaces whiskers C5-C2 and inhibited by caudal-to-rostral movements beginning at $\mathrm{C} 1$. Of 10 other cells examined in this fashion, one other displayed comparable properties, and on the basis of the microdrive reading $(1,590 \mu \mathrm{m})$ this cell appeared to also be located deep in the cortex. The remaining nine units displayed response suppression to three-whisker combinations that was qualitatively similar to that observed in the paired two-whisker paradigm.

These data suggest that directional selectivity may depend on the conjuction of several receptive-field characteristics: 1) the shape of the excitatory receptive field, 2) the distribution of inhibitory subregions, and 3) the angular sensitivity of the cell to individual whisker displacements. Thirty-two neurons had 
TABLE 2. Receptive-field organization of directionally selective neurons

\begin{tabular}{lccr}
\hline \hline & \multicolumn{3}{c}{ Conditioning Stimulus } \\
\cline { 2 - 4 } Angle/Spatial Order & PW & Non-PW & Total \\
\hline Parallel & 3 & 17 & 20 \\
Not parallel & 1 & 4 & 5 \\
Total & 4 & 21 & 25 \\
\hline
\end{tabular}

PW, principal whisker.

excitatory multiwhisker receptive fields and displayed two (or three) distinct response peaks when combinations of whiskers were deflected at 10- or 20-ms condition-test intervals (e.g., Figs. 5, 6, and 10). These cases were examined to determine the relationship between the angle of the whisker displacements and the spatial order of the combined deflection. Seven cells were discarded since the deflection angles could not be interpreted with respect to spatial order (e.g., combined displacements of $\mathrm{Cl}$ and C2 at 90 or $270^{\circ}$ ). Table 2 summarizes data from the remaining 25 cells and shows that in 20 cases the angle of the individual whisker movements roughly parallels the spatial order of the combined deflections (e.g., B2 precedes B1 at $45^{\circ}$ as in Fig. 5; see also Fig. 2 in Ref. 54). None of these cells was recorded in the middle depths of the cortex. In 17 of these cases, the conditioning stimulus was movement of a non-PW whisker. In nine instances, the overall direction of the stimuli was rostral to caudal, and in the remaining 11 cells the direction was caudal to rostral. For the other five cclls, the angle of the whisker displacements did not parallel the spatial order of the deflections (e.g., E4 precedes E3 at $180^{\circ}$ ), although in four cases the conditioning stimulus also consisted of a non-PW whisker. Again, all but two of the cells were located outside the middle depths of the cortex.

\section{DISCUSSION}

When whiskers are deflected in combination, the most commonly observed effect is a time-dependent reduction of SI cortical unit discharges to the second (or third) deflected whisker. Importantly, however, the presence and degree of this response suppression depends on a number of spatial factors. These include the angular direction(s) in which the hairs are moved, the sequence in which the whiskers are deflected, the particular combination of whiskers stimulated, and the number of whiskers involved. Identical stimuli elicit responses from first-order neurons that largely reflect the responses of these neurons to the individual whiskers deflected one at a time. These latter findings indicate that there is no integration of multiwhisker inputs at the levels of the trigeminal ganglion and are entirely consistent with numerous observations in a variety of species that a given afferent fiber in the trigeminal nerve functionally innervates one and only one mystacial vibrissa (e.g., Refs. $8,14,79)$. Temporal and spatial integration of multiwhisker inputs must therefore involve neuronal interactions within the central nervous system. The response properties of vibrissa units in the rodent SI cortex and of cutaneous units in the somatic sensory cortex of cats and primates suggest that such processing of sensory information depends at least in part on intracortical mechanisms.

\section{Temporal integration}

On the basis of single-unit recording studies in the somatosensory cortex of cats and monkeys, Mountcastle and his colleagues $(37,38)$ first demonstrated that somatic sensory stimuli evoke an initial excitation followed by a longer-lasting "afferent" inhibition within central neurons receiving inputs from ascending dorsal column-medial lemniscus pathways. Several subsequent studies have shown that one effect of this is a diminution in the responsiveness of cortical cells following a punctate cutaneous stimulus, displacement of a single facial vibrissa, and/or electrical shock to a peripheral nerve $(2,12,18,43)$. This decreased responsiveness is seen as a reduction in the number of unit discharges elicited by the second of two equally intense stimuli and is most pronounced during the $10-20 \mathrm{~ms}$ after the first stimulus. Results generally indicate a return in responsiveness within a period of 75-125 ms. There is clearly a spatial component to these temporal interactions because in general the strength of response suppression depends on the position of the first stimulus within the excitatory receptive field and decreases as the distance between the two stimulus loci increases (see below).

Afferent inhibition is observed in the dorsal column nuclei and in the ventrobasal thalamic 
complex, as well as in the somatosensory cortex (e.g., Ref. 15). It is interesting, however, that the time course of response suppression observed in the cortex parallels the temporal responsiveness of SI cortical neurons to sinusoidal stimulation of the skin $(10,39)$ or vibrissae $(18,53)$. For example, cortical neurons are limited in their ability to follow repetitive stimuli in a one-to-one fashion at frequencies greater than $\sim 40-80 \mathrm{~Hz}$. In contrast, recordings from presumed thalamocortical fibers to the somatosensory cortex have shown them to be entrainable by natural or electrical stimulation of the periphery to at least $200 \mathrm{~Hz}$ $(18,39)$. It is unlikely that the frequency-response properties of SI cortical neurons can be explained entirely on the basis of intrinsic membrane phenomena because it has recently been shown that pacinian neurons in SII can be entrained by higher-frequency vibration stimuli than pacinian neurons in SI (10). Taken together these observations suggest that a substantial transformation of temporal information occurs within the somatosensory cortex itself. Supporting evidence for this is provided by intracellular recording studies that demonstrate sequences of excitatory and inhibitory postsynaptic potentials (EPSP-IPSPs) or sometimes only a longer-latency IPSP in the initial responses of cortical neurons to cutaneous or vibrissal stimuli $(1,11,23,18,73)$. Hyperpolarization of the membrane potential is maximal $20-30 \mathrm{~ms}$ after stimulus onset and declines to resting levels over a period of $100-$ $150 \mathrm{~ms}$. Similar observations have been made recently in the rat SI vibrissa cortex using multiwhisker stimuli (Simons and Carvell, unpublished data). A cortical origin for such IPSPs is suggested by several lines of indirect evidence indicating that the specific thalamic input to the cortex is excitatory $(4,20,58,71)$.

\section{Spatial integration}

In several important respects the spatial organization of vibrissal receptive fields is comparable with that seen in other somatic sensory systems. For example, excitation and inhibition are both maximal at the physiologically defined focus of the receptive field (i.e., the principal whisker), and both decline in intensity at progressively more eccentric loci on the skin (or mystacial pad) surface $(12,25,38)$. Inhibitory effects decline somewhat more gradually and can be elicited over a broader area of the receptor periphery than excitation. With respect to cutaneous sensibility this organization is thought to limit the spread of excitation resulting from a focal cutaneous stimulus and thus enhance spatial resolution on a continuously innervated surface like the glabrous skin of the hand (38). A similar role for afferent inhibition may be proposed for the vibrissal system as well because it is unlikely that during whisking behavior a single vibrissa is ever deflected in isolation (see below).

A particularly interesting finding is that excitatory and inhibitory subregions of vibrissal receptive fields may be distributed asymmetrically with respect to the principal whisker and with respect to each other. Especially in the case of cells whose angular preferences parallel these asymmetries, such receptive fields take on a distinct spatial orientation. The dynamic aspects of this need to be investigated in greater detail using a larger stimulator array. Nevertheless, it appears that such intrinsic receptive-field organization could underlie the synthesis of complicated response properties, such as direction selectivity. Asymmetric distributions of inhibition and excitation have been proposed as mechanisms responsible for direction-selective responses of cutaneously driven neurons in areas 1 and 2 of primate cortex $(13,22)$. Some of the present findings suggest that cells having symmetrical or asymmetrical receptive fields constitute different populations of vibrissa neurons within the rodent SI cortex and that these two functional cell types may be differentially distributed among the cortical laminae, with asymmetrical units being located predominantly in the deeper part of the cortex. This would parallel the known relationship between excitatory receptive-field size and cortical depth in the rat somatosensory cortex $(5,27,53)$, as well as the laminar distribution of neurons with spatially oriented and nonoriented receptive fields in the primate somatosensory and visual cortices $(21,74)$.

\section{Cortical organization and function}

Findings from previous microelectrode studies of the SI barrel cortex indicate that one of its important functions is to integrate information arising from different, individual vibrissae on the contralateral face. This occurs within the context of a vertical or columnar 
organization that preserves certain features of the peripheral stimulus (i.e., which whisker is stimulated) and a horizontal organization, largely correlated with laminar patterns, that provides for spatial integration of inputs from closely related parts of the receptor surface (i.e., different whiskers). Thus, multiple-whisker receptive fields, which are largest and most numerous in nongranular layers, are thought to be elaborated in part by convergence of excitatory inputs from single-whisker neurons in the relevant layer IV barrels (see Ref. 53). The nature of this convergence is quite precise since, typically, responses elicited by stimulation of different vibrissae in a multiwhisker receptive field are qualitatively similar. The present data parallel these findings in suggesting specific inhibitory as well as excitatory interactions among cells located in neighboring barrels and the columns of which they are a part (see also Ref. 59). This is consistent with pharmacological studies of visual cortex that indicate an important role for $\gamma$-aminobutyric acid (GABA)-mediated inhibition in shaping the response patterns of cortical neurons to complicated stimulus events (50-52; see also Ref. 19). Inhibitory effects within the cortex are most likely mediated by smooth or sparsely spined stellate cells (see Ref. 29, 42) that may use GABA as a neurotransmitter (e.g., Ref. 45). In the barrels such cells appear to be ideally situated for exerting potent and spatially selective inhibitory effects $(30,31,48,57,70$, 76). There is now some direct evidence (33) that barrel neurons having smooth dendrites are synonymous with "fast-spike" units that are recorded infrequently, but predominantly in layer IV (see Ref. 53, 56, 57).

On the basis of presently available data, however, it is not possible to determine the extent to which the multiwhisker interactions observed in this study involve cortical mechanisms per se and/or reflect processing that occurs at lower levels of the ascending vibrissatrigeminal system. Convergence of spatial information, as evidenced by some neurons having multiwhisker receptive fields, has been documented in the brain stem trigeminal nuclei $(40,49)$ and in the thalamic ventrobasal complex (65) so that spatial and temporal integration could occur prior to the arrival of information in the cortex. For example spatial summation in response to simultaneous deflection of several whiskers has been observed in physiologically identified relay neurons in the brain stem of cats (16). This is seen as an increase in unit discharge frequency or in some cases as a qualitative change in the discharge pattern, such as the addition of a tonic or sustained component that is not observed when only one whisker is stimulated. This latter observation is particularly interesting in light of the data presented in Fig. 10. Temporal integration of multiwhisker inputs could also involve short-latency feedback loops linking brain stem and/or thalamic neurons with cortical cells by means of corticofugal projection neurons (see Ref. 72). As regards the contributions of the somatosensory thalamus, however, it is significant that recent anatomical and histochemical studies have shown the ventrobasal complex of rats to be unusual among mammalian species in its apparent lack of intrinsic interneurons $(41,44,46,69)$. These findings suggest that the processing of multiwhisker inputs in the rat thalamus may not be sufficient to account for the spatially specific types of inhibitory interactions found in the present study of cortical vibrissa neurons.

\section{Information processing in the vibrissal system}

Observations of rodent behavior have implicated a key role for the mystacial vibrissae in a variety of sensory discriminative, motor, and social behaviors (62; for a review see Ref. 17). Unfortunately, remarkably little is known of the tactile sensitivity and informational capacity of the vibrissa system because sensory functions of the vibrissae have been inferred largely on the basis of behavioral deficits observed after the whiskers have been removed. Neurophysiological data suggest a tactile system capable of considerable spatial and temporal resolution because neurons have been found at all levels of the rodent vibrissa-barrel system that encode aspects of a vibrissal stimulus such as its angular displacement, velocity, amplitude, and temporal pattern $(24,49,53$, $65,79)$. Moreover, the present findings suggest that some neurons in the SI cortex may in fact be differentially responsive to patterns of sensory input created by the relative movement of objects in certain directions and/or at certain velocities across the vibrissal field. In a natural setting such stimuli would be produced as the vibrissae are "whisked" through the sensory environment, each hair in turn con- 
tacting a stationary or moving object that is in close proximity to the animal's face. The whiskers are moved rhythmically at a frequency of $5-11 / \mathrm{s}$, with retraction occurring twice as fast as protraction (68). At $20 \mathrm{~mm}$ from the skin surface the large vibrissae in row $\mathrm{C}$ are separated from each other by $8-10 \mathrm{~mm}$. Assuming an average peak-to-peak amplitude of $\sim 25 \mathrm{~mm}$ (total excursion of $50 \mathrm{~mm} /$ cycle), adjacent vibrissae might be expected to sequentially strike a stationary object at intervals of roughly 12-25 ms during backward sweeps and 25-55 ms during forward movements. This overall time span corresponds to the period during which neuronal mechanisms in the central nervous system appear to be most effective in shaping the responses of single neurons to spatially patterned multiwhisker inputs. Future studies directly correlating

\section{REFERENCES}

1. ANDERSON, S. A. Intracellular postsynaptic potentials in the somatosensory cortex of the cat. Nature London 205: 297-298, 1965.

2. ANGEL, A. Cortical responses to paired stimuli applied peripherally and at sites along the somato-sensory pathway. J. Physiol. London 191: 427-448, 1967.

3. Axelrad, H., Verley, R., and Farkas, E. Responses evoked in mouse and rat SI cortex by vibrissa stimulation. Neurosci. Lett. 3: 265-274, 1976.

4. Bullier, J. AND Henry, G. H. Ordinal position and afferent input of neurons in monkey striate cortex. $J$. Comp. Neurol. 193: 913-935, 1980.

5. Chapin, J. K., Chia-Sheng, L., ANd Woodward, D. J. Laminar differences in the size and shape of receptive fields in rat somatosensory (SI) cortex. $\mathrm{Neu}$ rosci. Abstr. 6: 62, 1980.

6. Chapin, J. K., WATERhouse, B. D., AND WOODWARD, D. J. Differences in cutaneous sensory response properties of single somatosensory cortical neurons in awake and halothane anesthetized rats. Brain Res. Bull. 6: 63-70, 1981.

7. Durham, D. AND WoOlsey, T. A. Barrels and columnar cortical organization: evidence from 2-deoxyglucose (2-DG) experiments. Brain Res. 137: 169174, 1977.

8. DYKES, R. W. Afferent fibers from mystacial vibrissae of cats and seals. J. Neurophysiol. 38: 650-662, 1975.

9. EMMERS, R. Organization of the first and second somesthetic regions (SI and SII) in the rat thalamus. J. Comp. Neurol. 124: 215-228, 1965.

10. Ferrington, D. G. AND Rowe, M. Differential contributions to coding of cutaneous vibratory information by cortical somatosensory areas I and II. $J$. Neurophysiol. 43: 310-331, 1980.

11. FOMOVSKII, B. I. Responses of neurons in the vibrissae projection area of the cat somatosensory cortex to afferent activation. Neirofiziologiya 11: 550-559, 1979.

12. Gardner, E. P. And Costanzo, R. M. Temporal neurophysiological and sensory data obtained in well-defined behavioral settings should prove valuable in defining the capabilities of this highly organized sensory system and for establishing the role of the somatosensory cortex in processing tactile information.

\section{ACKNOWLEDGMENTS}

I thank Glenn Fleet and Greg Szekeres for expert technical assistance, Sandy Estocsin for typing, and my colleagues P. W. Land and G. E. Carvell for critically reading the manuscript. This report is dedicated to the late Dr. Thomas T. Sandel with whom I first discussed these experiments.

This work was supported by grants from the National Science Foundation (BNS80-21854) and the National Institutes of Health (NS-19950).

Received 17 September 1984; accepted in final form 28 March 1985. integration of multiple-point stimuli in primary somatosensory cortical receptive fields of alert monkeys. J. Neurophysiol. 43: 444-468, 1980.

13. Gardner, E. P. And Costanzo, R. M. Neuronal mechanisms underlying direction sensitivity of somatosensory cortical neurons in awake monkeys. $J$. Neurophysiol. 43: 1342-1354, 1980.

14. Gottschaldt, K. M., IgGo, A., AND Young, D. Functional characteristics of mechanoreceptors in sinus hair follicles of the cat. J. Physiol. London 235: 287-315, 1973.

15. GotTschaldT, K. M. AND YounG, D. W. Properties of different functional types of neurones in the cat's rostral trigeminal nuclei responding to sinus hair stimulation. J. Physiol. London 272: 57-84, 1977.

16. GotTsChaldT, K. M. AND YounG, D. W. Quantitative aspects of responses in trigeminal relay neurons and interneurons following mechanical stimulation of sinus hairs and skin in the cat. J. Physiol. London 272: 85-103, 1977.

17. Gustafson, J. W. and Felbain-Keramidas, S. L. Behavioral and neural approaches to the function of the mystacial vibrissae. Psychol. Bull. 84: 477-488, 1977.

18. HeillweG, F. C., Schultz, W., And CreutzFeldt, O. D. Extracellular and intracellular recordings from cat's cortical whisker projection area: thalamocortical response transformation. J. Neurophysiol. 40: 463479, 1977.

19. Hicks, T. P. AND DYKES, R. W. Receptive field size for certain neurons in primary somatosensory cortex is determined by GABA-mediated intracortical inhibition. Brain Res. 274: 160-164, 1983.

20. Hicks, T. P. AND Guedes, R. C. A. Neuropharmacological properties of electrophysiologically identified, visually responsive neurones of the posterior lateral suprasylvian area. Exp. Brain Res. 49: 157-173, 1983.

21. HubEL, D. H. AND WIESEL, T. N. Receptive fields 
and functional architecture of monkey striate cortex. J. Physiol. London 195: 215-243, 1968.

22. HYVÄRINEN, J. AND PORANEN, A. Movement-sensitive and direction and orientation-selective cutaneous receptive fields in the hand area of the postcentral gyrus in monkeys. J. Physiol. London 283: 523-537, 1978.

23. InNOCENII, G. M. AND MANZONI, T. Response patterns of somatosensory cortical neurons to peripheral stimuli. An intracellular study. Arch. Ital. Biol. 110: 322-347, 1972.

24. ITO, M. Some quantitative aspects of vibrissa-driven neuronal responses in rat neocortex. J. Neurophysiol. 46: 705-715, 1981

25. JÄNIG, W., SPENCER, W. A., AND YOUNKIN, G. Spatial and temporal features of afferent inhibition of thalamocortical relay cells. J. Physiol. London 42: 1450-1460, 1979.

26. Killackey, H. P., Belford, G., Ryugo, R., AND RYUGO, D. K. Anomalous organization of thalamocortical projections consequent to vibrissae removal in the newborn rat and mouse. Brain Res. 104: $309-315,1976$.

27. LAmour, Y., Guilbaud, G., AND Willer, J. C. Rat somatosensory (SmI) cortex. II. Laminar and columnar organization of noxious and non-noxious inputs. Exp. Brain Res. 49: 46-54, 1983.

28. LEE, K. J. AND WOOLSEY, T. A. A proportional relationship between peripheral innervation density and cortical neuron number in the somatosensory system of the mouse. Brain Res. 99: 349-353, 1975.

29. LeVAY, S. Synaptic patterns in the visual cortex of the cat and monkey. Electron microscopy of Golgi preparations. J. Comp. Neurol. 150: 53-86, 1973.

30. I ORENTE DE Nó, R. La corteza cerebral del raton. Trab. Lab. Invest. Biol. Madrid 20: 41-78, 1922.

31. Lu, S. M., SCHMECHEL, D. E., AND Lin, C.-S. Glutamic acid decarboxylase immunoreactivity in layer IV of barrel fields in normal and neonatal whisker manipulated rats and mice. Soc. Neurosci. Abstr. 10: 494, 1984.

32. LUMB, W. V. AND JONES, E. W. Veterinary Anesthesia, Philadelphia, PA: Lea \& Febiger, 1973.

33. MCCORMICK, D. A., CONNORS, B. W., Lighthall, J. W., AND PRINCE, D. A. Comparative electrophysiology of pyramidal and sparsely spiny neurons of the neocortex. $J$. Neurophysiol. In press.

34. McKenna, T. M., Light, A. R., AND Whitsel, B. L. Neurons with unusual response and receptivefield properties in upper laminae of cat SI cortex. $J$. Neurophysiol. 51: 1055-1076, 1984.

35. MCKenna, T. M., Whitsel, B. L., AND DREyer, D. A. Anterior parietal cortical topographic organization in macaque monkey: a reevaluation. $J$. Neurophysiol. 48: 289-317, 1982.

36. Mountcastle, V. B. Modality and topographic properties of single neurons of cat's somatic sensory cortex. J. Neurophysiol. 20: 407-434, 1957.

37. Mountcastle, V. B., Davies, P. W., and Berman, A. L. Response properties of neurons of cat's somatic sensory cortex to peripheral stimuli. $J$. Neurophysiol. 20: 374-407, 1957.

38. Mountcastle, V. B. And Powell, T. P. S. Neural mechanisms subserving cutaneous sensibility, with special reference to the role of afferent inhibition in sensory perception and discrimination. Bull. Johns Hopkins Hosp. 105: 201-232, 1959.
39. Mountcastle, V. B., Talbot, W. H., Sakata, H., AND HYVÄRINEN, J. Cortical neuronal mechanisms in flutter-vibration studied in unanesthetized monkeys. Neuronal periodicity and frequency discrimination. J. Neurophysiol. 32: 452-484, 1969.

40. NORD, S. G. Somatotopic organization in the spinal trigeminal nucleus, the dorsal column nuclei and related structures in the rat. J. Comp. Neurol. 130: 343$355,1967$.

41. Peschanski, M., Ralston, H. J., AND Roudier, F. Reticularis thalami afferents to the ventrobasal complex of the rat thalamus: an electron microscope study. Brain Res. 270: 325-329, 1983.

42. Peters, A. AND Fairén, A. Smooth and sparselyspined stellate cells in the visual cortex of the rat: a study using a combined Golgi-electron microscope technique. J. Comp. Neurol. 181: 129-172, 1978.

43. Pubols, L. M., Leroy, R. F., AND Pubols, J. F. Response of raccoon SI neurons to temporally distributed tactile stimuli applied to the forepaw. Brain Res. 132: 558-561, 1977.

44. Ralston, H. J. Synaptic organization of spinothalamic tract projections to the thalamus, with special reference to pain. In: Advances in Pain Research and Therapy, edited by L. Kruger and J. C. Licbeskind. New York: Raven, 1984, p. 183-195.

45. RIBAK, C. E. Aspinous and sparsely-spinous stellate neurons in the visual cortex of rats contain glutamic acid decarboxylase. I. Neurocytol. 7: 461-478, 1978.

46. SAPPORTA, S. AND KRUGER, L. The organization of thalamocortical relay neurons in the rat ventrobasal complex studied by the retrograde transport of horseradish peroxidase. J. Comp. Neurol. 174: 187-208, 1977.

47. Schultz, W., Galbraith, G. C., Gottschaldt, K. M., AND CREUTzFELDT, O. D. A comparison of primary afferent and cortical neurone activity coding sinus hair movements in the cat. Exp. Brain Res. 26: 365-381, 1976.

48. SENFT, S. Interactive computer-graphical representation of calculated voltages over three-dimensional arborizations of individual neurons. Soc. Neurosci. Abstr. 9: 679, 1983.

49. Shipley, M. T. Response characteristics of single units in the rat's trigeminal nuclei to vibrissa displacements. J. Neurophysiol. 37: 73-90, 1974.

50. Sillito, A. M. The contribution of inhibitory mechanisms to the receptive field properties of neurons in the striate cortex of the cat. J. Physiol. London 250: 305-329, 1975.

51. Sillito, A. M. Inhibitory processes underlying the directional specificity of simple, complex and hypercomplex cells in the cat's visual cortex. J. Physiol. London 271: 699-720, 1977.

52. Sillito, A. M. Orientation selectivity and the spatial organization of the afferent input to the striate cortex (Abstract). Exp. Brain Res. 41: A9, 1980.

53. SIMONS, D. J. Response properties of vibrissa units in rat SI somatosensory neocortex. J. Neurophysiol. 41: 798-820, 1978.

54. SimONS, D. J. Multi-whisker stimulation and its effects on vibrissa units in rat SmI barrel cortex. Brain Res. 276: 178-182, 1983.

55. Simons, D. J., Durham, D., And Woolsey, T. A. Functional organization of mouse and rat SmI barrel cortex following vibrissal damage on different postnatal days. Somatosensory Res. 1: 207-245, 1984. 
56. Simons, D. J. AND WoOlsey, T. A. Functional organization in mouse barrel cortex. Brain Res. 165: 327-332, 1979.

57. Simons, D. J. AND WoOlSEY, T. A. Morphology of Golgi-Cox impregnated barrel neurons in rat SmI cortex. J. Comp. Neurol. 230: 119-132, 1984.

58. Stone, T. W. Cholinergic mechanisms in the rat somatosensory cerebral cortex. J. Physiol. London 225: 485-499, 1972.

59. UHR, J. L. AND CHAPIN, J. K. Contribution of thalamo-cortical and corticocortical connections to receptive field properties in the rat SmI cortex. Soc. Neurosci. Abstr. 9: 250, 1983.

60. VAN DER LOOS, H. AND WOOLSEY, T. A. Somatosensory cortex: structural alterations following early injury to sense organs. Science 179: 345-398, 1973.

61. VERLEY, R. AND ONNEN, I. Somatotopic organization of the tactile thalamus in normal adult and developing mice and in adult mice dewhiskered since birth. Exp. Neurol. 72: 462-474, 1981.

62. VINCENT, S. B. The function of the vibrissae in the behavior of the white rat. Behav. Monographs 1: 7$85,1912$.

63. VINCENT, S. B. The tactile hair of the white rat. $J$. Comp. Neurol. 23: 1-38, 1913.

64. WAITE, P. M. E. Somatotopic organization of vibrissal responses in the ventrobasal complex of the rat thalamus. J. Physiol. London 228: 527-540, 1973a.

65. WAITE, P. M. E. The responses of cells in the rat thalamus to mechanical movements of the whiskers. $J$. Physiol. London 228: 541-561, 1973b.

66. WELKER, C. Microelectrode delineation of the fine grain somatotopic organization of SmI cerebral neocortex in albino rat. Brain Res. 26: 259-275, 1971.

67. WELKER, C. Receptive fields of barrels in the somatosensory neocortex of the rat. J. Comp. Neurol. 166: 173-190, 1976.

68. WELKER, W. Analysis of sniffing of the albino rat. Behaviour 22: 223-244, 1964.

69. Wells, J., Mathews, T. J., AND ARiano, M. A. Are there interneurons in the thalamic somatosensory projection nucleus in the rat. Soc. Neurosci. Abstr. 8: $37,1982$.

70. WHITE, E. L. Identified neurons in mouse SmI cortex which are postsynaptic to thalamocortical axon terminals: a combined Golgi-electron microscope and degeneration study. J. Comp. Neurol. 181: 627-662, 1978.

71. WHITE, E. L. Thalamocortical synaptic relations: a review with emphasis on projections of specific thalamic nuclei to the primary sensory areas of the neocortex. Brain Res. Rev. 1: 275-311, 1979.

72. WhITE, E. L. AND HERSCH, S. M. A quantitative study of thalamocortical and other synapses involving the apical dendrites of corticothalamic projection cells in mouse SmI cortex. J. Neurocytol. 11: 137-157, 1982.

73. Whitehorn, D. AND TOWE, A. L. Postsynaptic potential patterns evoked upon cells in sensorimotor cortex of cat by stimulation at the periphery. Exp. Neurol. 22: 222-242, 1968.

74. Whitsel, B. L., RopPolo, J. R., AND WeRner, G. Cortical information processing of stimulus motion on primate skin. J. Neurophysiol. 35: 691-717, 1972.

75. WoOLSEY, T. A. Somatosensory, auditory and visual cortical areas of the mouse. Johns Hopkins Med. J. 121: $91-112,1967$.

76. WoOlsey, T. A., Dierker, M. L., AND WANN, D. F. Mouse SmI cortex: qualitative and quantitative classification of Golgi-impregnated barrel neurons. Proc. Natl. Acad. Sci. USA 72: 2165-2169, 1975.

77. WOOLSEY, T. A. AND VAN DER LOOS, H. The structural organization of layer IV in the somatosensory region (SI) of mouse cerebral cortex: the description of a cortical field composed of discrete cytoarchitectonic units. Brain Res. 17: 205-242, 1970.

78. WoOlsey, T. A., Welker, C., AND SChWartz, R. H. Comparative anatomical studies of the SmI face cortex with special reference to the occurrence of "barrels" in layer IV. J. Comp. Neurol. 164: 79-94, 1975.

79. ZUCKER, E. AND WELKER, W. I. Coding of somatic sensory input by vibrissal neurons in the rat's trigeminal ganglion. Brain Res. 12: 138-156, 1969. 